\title{
Pharmacokinetic Characteristics of Long-Acting Injectable Antipsychotics for Schizophrenia: An Overview
}

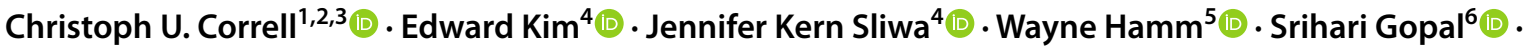 \\ Maju Mathews $^{6}$ (1) $\cdot$ Raja Venkatasubramanian $^{6}$ (I) Stephen R. Saklad ${ }^{7,8} \oplus$
}

Accepted: 23 November 2020 / Published online: 28 January 2021

(c) The Author(s) 2021

\begin{abstract}
The availability of long-acting injectable (LAI) antipsychotics for the treatment of schizophrenia provides clinicians with options that deliver continuous drug exposure and may improve adherence compared with daily oral antipsychotics. However, all LAI antipsychotics have unique formulations and pharmacokinetic characteristics that have implications for medication selection, administration interval, and injection site. This review outlines key differences in drug formulations and pharmacokinetics among LAI antipsychotics. A systematic search of the PubMed database was conducted to identify physical and formulation properties and pharmacokinetic data of commercially available LAI antipsychotics, including flupentixol decanoate, fluphenazine decanoate, haloperidol decanoate, zuclopenthixol decanoate, aripiprazole monohydrate, aripiprazole lauroxil, olanzapine pamoate, paliperidone palmitate, risperidone microspheres, and risperidone polymeric microspheres. Additional information was obtained from package inserts and product monographs. Relevant data on drug properties, administration details, pharmacokinetic parameters, and oral dose equivalencies of LAI antipsychotics are summarized. Based on our analysis, formulation characteristics (e.g., vehicle medium) and administration characteristics (e.g., injection site) can affect rate of absorption and adverse effects and may factor into whether oral supplementation or an additional injection is needed. Dose adjustments may be necessary based on potential drug-drug interactions, and approximate dose equivalence with oral formulations can help inform titration when switching from oral to LAI formulations. Clinicians administering LAI antipsychotics should consider these formulation and pharmacokinetic factors to maximize clinical impact and to adjust to an individual patient's needs and treatment goals.
\end{abstract}

Supplementary Information The online version contains supplementary material available at https://doi.org/10.1007/s4026 3-020-00779-5.

Stephen R. Saklad

Saklad@uthscsa.edu

1 Department of Psychiatry and Molecular Medicine, Donald and Barbara Zucker School of Medicine at Hofstra/ Northwell, Hempstead, NY, USA

2 Division of Psychiatric Research, Zucker Hillside Hospital, Glen Oaks, NY, USA

3 Department of Child and Adolescent Psychiatry, Charité Universitätsmedizin Berlin, Berlin, Germany

4 Janssen Scientific Affairs, LLC, Titusville, NJ, USA
5 Janssen Scientific Affairs, LLC, Spring Hill, TN, USA

6 Janssen Research and Development, LLC, Titusville, NJ, USA

7 College of Pharmacy, Pharmacotherapy Division, The University of Texas at Austin, 7703 Floyd Curl Drive, MC 6220, San Antonio, TX 78229-3900, USA

8 Long School of Medicine, Pharmacotherapy Education and Research Center, UT Health San Antonio, San Antonio, TX 78229-3900, USA 


\section{Key Points}

Long-acting injectable (LAI) antipsychotics have several advantages over oral antipsychotics, including ensuring clinician awareness of nonadherence due to absence or tardiness at injection appointments, reduction in pill burden, and reduced consequences of planned or unplanned treatment gaps, such as risk of relapse, hospitalization, and increased mortality.

Pharmacokinetic characteristics of LAI antipsychotics impact their rate of absorption, the severity and frequency of associated adverse effects, and drug-drug interactions.

Understanding the unique pharmacokinetic characteristics of commercially available LAI antipsychotics and the clinical implications of these properties is critical for appropriate drug selection, dosing, and administration.

\section{Introduction}

Schizophrenia is a disabling chronic disorder characterized by positive, negative, and cognitive symptoms, and in which acute psychotic episodes are interspersed with periods of relative symptom control and maintenance $[1,2]$. Antipsychotic medications are a fundamental element of treatment used to reduce intensity and frequency of symptoms [3]. Long-term, consistent treatment with antipsychotic medication is important to achieve and maintain symptom control. Estimates of discontinuation rates for oral antipsychotics range from 26 to $44 \%$, with as many as two-thirds of patients being at least partially nonadherent [4]. Disruption of treatment coverage has been associated with symptom relapse and increased risk of hospitalization [5-7]. Psychotic relapse is extremely disruptive to patients and their families and is associated with multiple downstream effects on disease course and brain structure [2], such as progressive decline in gray and white matter structure and volume [8,9]. Relapses may also lead to reduced response to previously effective antipsychotics, potentially contributing to treatment resistance [10-12].

Long-acting injectable (LAI) antipsychotics, originally called depot antipsychotics, were developed to enable maintenance of stable plasma drug concentrations and consequently reduce the risk of relapse and adverse events [13]. LAIs have a few advantages over oral antipsychotics, including ensuring clinician awareness of nonadherence due to absence or tardiness at injection appointments, reduction in pill burden, and reduced consequences of planned or unplanned treatment gaps. However, there are substantial differences between the pharmacokinetic characteristics of oral and LAI antipsychotics that must be considered when prescribing LAIs. The present review will help clinicians understand the unique pharmacokinetic characteristics of commercially available LAI antipsychotics and the clinical implications of these characteristics.

\subsection{Pharmacokinetics Overview}

Pharmacokinetics is defined as the characteristics of drug absorption, distribution, metabolism, and elimination in the body $[14,15]$. After administration, all medications undergo several discrete processes that impact their pharmacokinetics, which for a specific dosage regimen describes the time course of drug concentration as the drug moves through different areas of the body $[14,15]$. Dosage regimens are determined through appropriate application of pharmacokinetic principles to achieve a desired drug concentration in the plasma and produce an expected therapeutic response with minimal toxicity.

Absorption refers to the transfer of the drug from its site of administration into systemic circulation. Absorption is a key determinant of $\mathrm{t}_{\max }$, the time to reach maximal plasma concentration $\left(C_{\max }\right)$ [15]. See Table 1 in the Electronic Supplementary Material (ESM) for a glossary of key pharmacokinetic parameters, and Fig. 1 in the ESM for a sample plasma concentration-time curve. The rate of absorption can be profoundly affected by the drug formulation and route of administration [16, 17], which has implications for the onset and duration of action for oral and LAI antipsychotics. Drugs administered via oral, intramuscular, or subcutaneous routes are absorbed prior to entering systemic circulation, while drugs administered intravenously enter the circulation directly. The fraction of the administered dose that enters into the systemic circulation is referred to as its bioavailability $(F)$, which is $100 \%$ for an intravenous formulation [15]. Total exposure to the drug over time can be assessed by calculating the area under the plasma concentration-time curve (AUC). The bioavailability of an oral drug can be determined by calculating its AUC as a percentage of the AUC for the intravenous formulation [15]. Distribution refers to the movement of the drug from the systemic circulation to other tissues (i.e., different areas of the body) [14]. The volume of distribution, $V_{\mathrm{d}}$, represents the volume in which a drug either remains in the plasma or redistributes to other tissue compartments. It is a proportionality constant used to describe the total amount of drug in the body in relation to the plasma concentration $(\mathrm{Cp})$ of the drug at a given time [18]. In other words, if the entire dose were absorbed, the $V_{\mathrm{d}}=$ dose $/$ Cp. Larger values of $V_{\mathrm{d}}$ (e.g., $>3 \mathrm{~L}$ ) indicate that more drug is distributed in the tissue than in the plasma [14]. Metabolism is the chemical modification of the drug within the body [14]. During this process, the drug can be transformed into metabolites that are generally more hydrophilic 
A

$$
C_{p}=\frac{\left(k_{\text {fast }}\right)(F)(\text { Dose })}{V_{d}\left(k_{\text {fast }}-k_{\text {slow }}\right)}\left(e^{\left.-k_{\text {slowt }}-e^{-k \text { fast }}\right)}\right.
$$

B
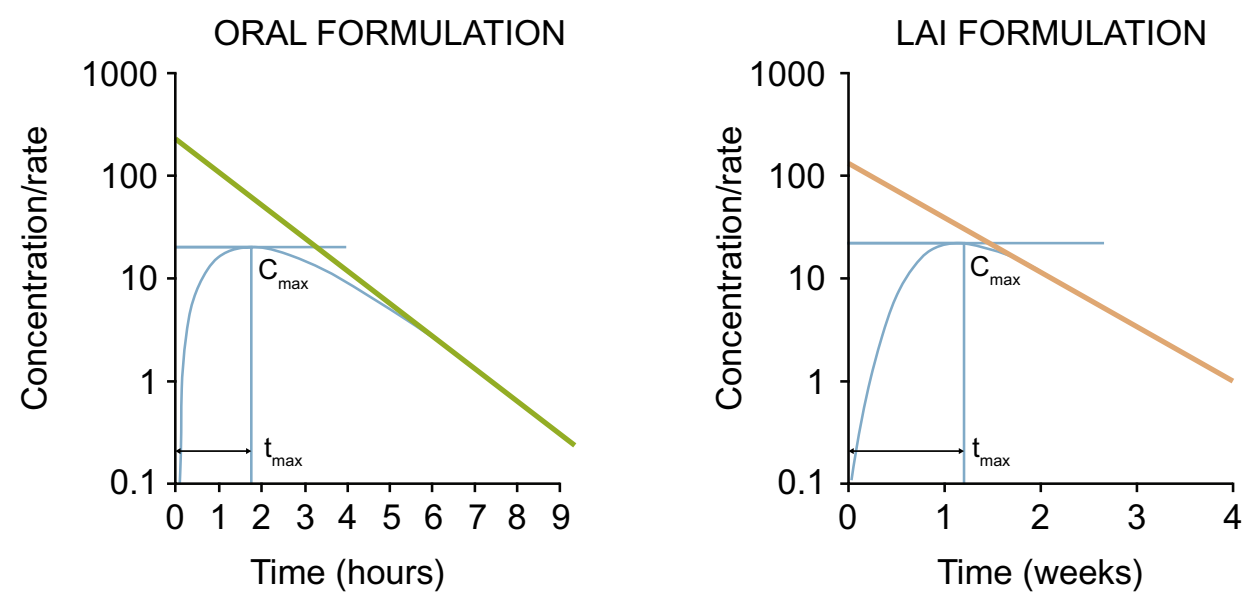

$\begin{array}{ll}\text { - } & \text { Elimination rate } \\ -\quad \text { Absorption rate } \\ \text { - } \quad \text { Plasma/blood concentration }\end{array}$

Fig. 1 Flip-flop pharmacokinetics. A Equation used to calculate concentration at time $t$. B Representative concentration-time curves. $C_{\text {max }}$ maximum concentration, $\mathrm{C} p$ plasma concentration at time $t$, $F$ bioavailability, $k_{\text {fast }}$ absorption rate constant for an oral drug and

(water soluble) and easier to eliminate. Metabolites that have a similar pharmacologic effect as the parent drug are called active metabolites [15]. The combined parent drug and active metabolite(s) is referred to as the active moiety [19]. Elimination is a term that involves both metabolism and excretion [20]. Excretion is the removal of the drug and its metabolites from the body via the kidneys or liver. The time required for $50 \%$ of a drug to be eliminated in the terminal phase is typically the elimination half-life $\left(t_{1 / 2}\right)$. The time needed to reach steady state is when the amount of drug administered is equivalent to the amount of drug eliminated within the dosing period. Attainment of steady state is not a linear process. It typically occurs after $4-5$ half-lives, when $93.8-96.9 \%$ of the final steady state has been reached. The longest half-life controls time to steady state. For most oral medications, the longest half-life is the elimination half-life, but for LAIs is the absorption half-life. elimination rate constant for an LAI, $k_{\text {slow }}$ absorption rate constant for an LAI and elimination rate constant for an oral drug, LAI long-acting injectable, $t$ time, $t_{\max }$ time to maximum concentration, $V_{d}$ volume of distribution

\subsection{Pharmacokinetics by Formulation}

Oral antipsychotics are absorbed either sublingually (currently only asenapine) [21] or in the gastrointestinal tract prior to reaching systemic circulation [20]. Several factors can influence the rate and extent of absorption of oral antipsychotics, including drug dissolution, drug solubility, susceptibility to enzymatic reactions, gastric $\mathrm{pH}$, drug-drug interactions, and food-drug interactions [22-24]. For orally administered drugs absorbed in the gastrointestinal tract, the drug first passes through the liver and intestines before reaching systemic circulation [25-27]. As the liver is the major site of metabolism, the drug might be metabolized, to some extent, before it reaches the circulation; this "first-pass effect" can significantly reduce the bioavailability of some drugs [25]. The family of 
cytochrome P450 (CYP) alleles, primarily found in liver cells, is involved in the metabolism of $70-90 \%$ of drugs [28, 29]. Patient-related factors such as impaired hepatic function or age-related decline in liver function can result in reduced first-pass clearance and therefore may result in higher bioavailability for some drugs [30]. CYP enzymes and $P$-glycoprotein (P-gp) are also expressed in the intestines, which may further lower systemic concentrations [26, 27]. Changes in CYP enzyme activity can necessitate dosing adjustments. For example, increases in drug concentration due to coadministered medications that inhibit CYP2D6 and CYP3A4 activity can lead to adverse events. Conversely, decreases in drug concentration due to induction of metabolic enzymes by coadministered drugs can result in loss of efficacy [31]. Notably, for immediate-release oral drug formulations, the absorption rate is faster than the elimination rate [32].

The pharmacokinetic profiles of LAI antipsychotics are quite different compared with those of oral antipsychotics. LAI antipsychotics are injected intramuscularly or subcutaneously, and the drug is slowly absorbed from the injection site into the circulation [33]. Absorption from the injection site can be influenced by properties of the drug, including water solubility and the delivery vehicle, and patient factors such as body weight, subcutaneous fat, and vascularity of the site of injection $[25,34,35]$. For most of the LAI preparations, a large percentage of the injected product initially remains in the injection area. Therefore, the absorption rate of LAI antipsychotics is slower than the elimination rate, resulting in "flip-flop" kinetics, whereby the time to steady state is a function of absorption, and the concentration at steady state is a function of elimination (Fig. 1) [32, 33]. The "apparent half-life" reflects that LAI antipsychotics exhibit a very slow and gradual absorption from the injection site, which drives the extended duration of blood concentrations. Once the drug is absorbed from the injection site into the bloodstream, the distribution and elimination of LAI antipsychotics is the same as after oral dosing. Non-oral routes of administration for some LAIs may avoid first-pass metabolism in the liver, which increases their bioavailability relative to that achieved after oral dosing [20]. The slower absorption rate of LAIs compared with oral antipsychotics in some cases leads to reduced peak $\left(C_{\max }\right)$ to trough $\left(C_{\min }\right)$ plasma concentration differences, which may be associated with fewer adverse effects and may contribute to better

\section{Peak-to-trough plasma concentration ratio at steady state}

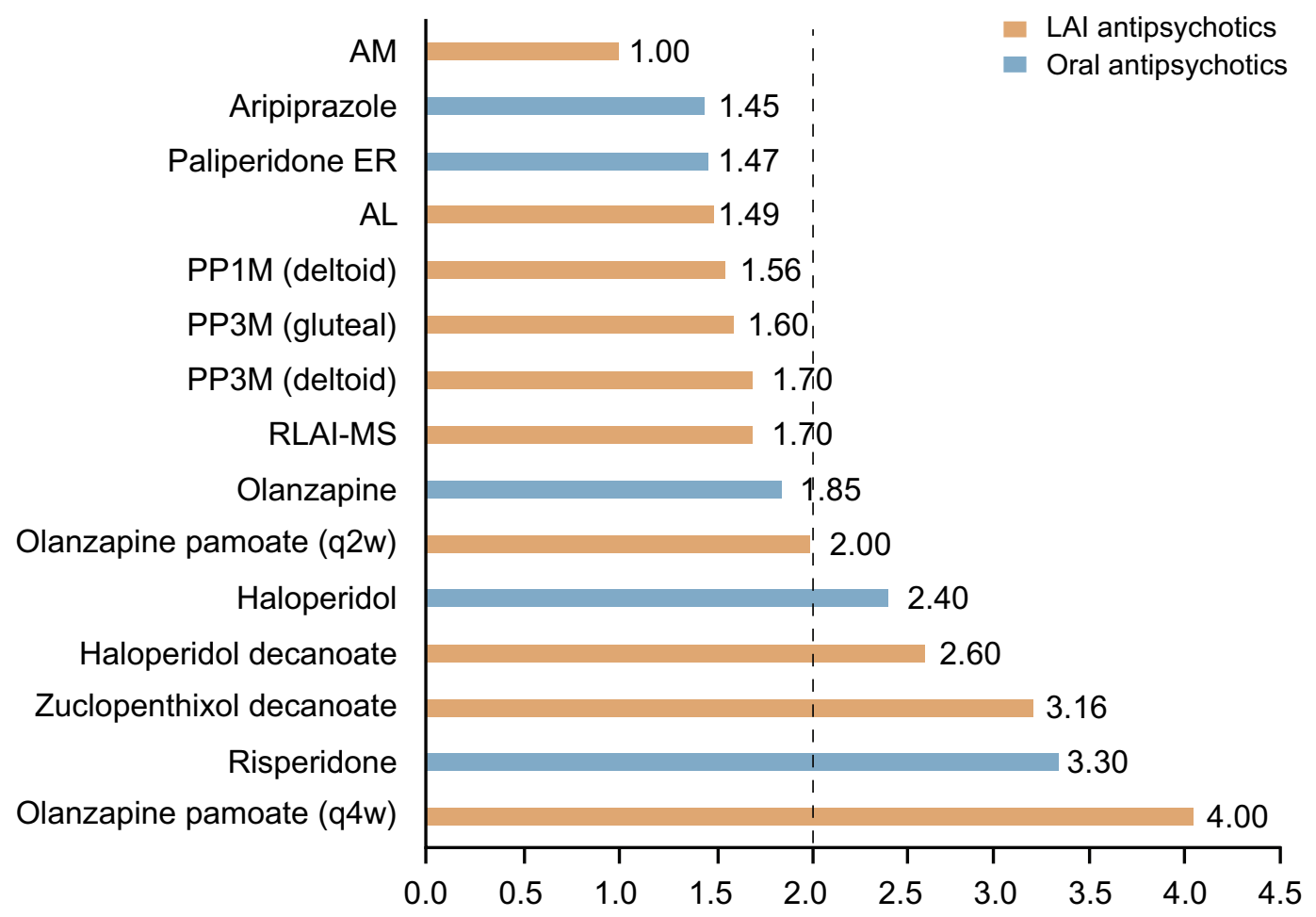

Fig. 2 Peak-to-trough plasma concentration ratios of oral and longacting injectable antipsychotics at steady state [36, 118-121]. $A L$ aripiprazole lauroxil, $A M$ aripiprazole monohydrate, $E R$ extended release, LAI long-acting injectable, PPIM paliperidone palmitate once monthly, PP3M paliperidone palmitate every 3 months, qxw every x weeks, RLAI-MS risperidone long-acting injection microspheres 
tolerability [36]. Peak-to-trough plasma concentrations vary widely across antipsychotics and can be affected by differences in dosing and formulation [36]. Larger fluctuations in peak-to-trough concentrations may negatively impact clinical response and tolerability [36]. Specifically, peak concentration is an indicator of the severity of adverse effects [36]. To date, antipsychotic formulations and dosing intervals resulting in a peak-to-trough fluctuation of two or less may offer a reasonable balance between efficacy and tolerability (Fig. 2) [36].

This review summarizes the pharmacokinetic characteristics and formulation properties of all commercially available LAI antipsychotics, which can inform appropriate usage and maximize clinical impact.

\subsection{Literature Search}

On 17 October 2018, a systematic literature search of the PubMed database was performed using the following search terms and Boolean search operators: (Long-acting OR depot OR injectable) AND (antipsychotic* OR neuroleptic*) AND (pharmacokinetic* OR PK). All search terms were limited to the English language, and no other database filters were used. Reference lists of selected papers were reviewed to identify additional relevant studies. Abstract results were manually screened to only include articles relevant to the study objective (i.e., all clinical studies and pharmacokinetic modeling studies with relevant pharmacokinetic data of LAI antipsychotics). Preclinical studies, review articles, guidelines, correspondence, opinion papers, commentaries, and editorials were excluded. Any literature with a primary focus on oral antipsychotics, antipsychotics withdrawn

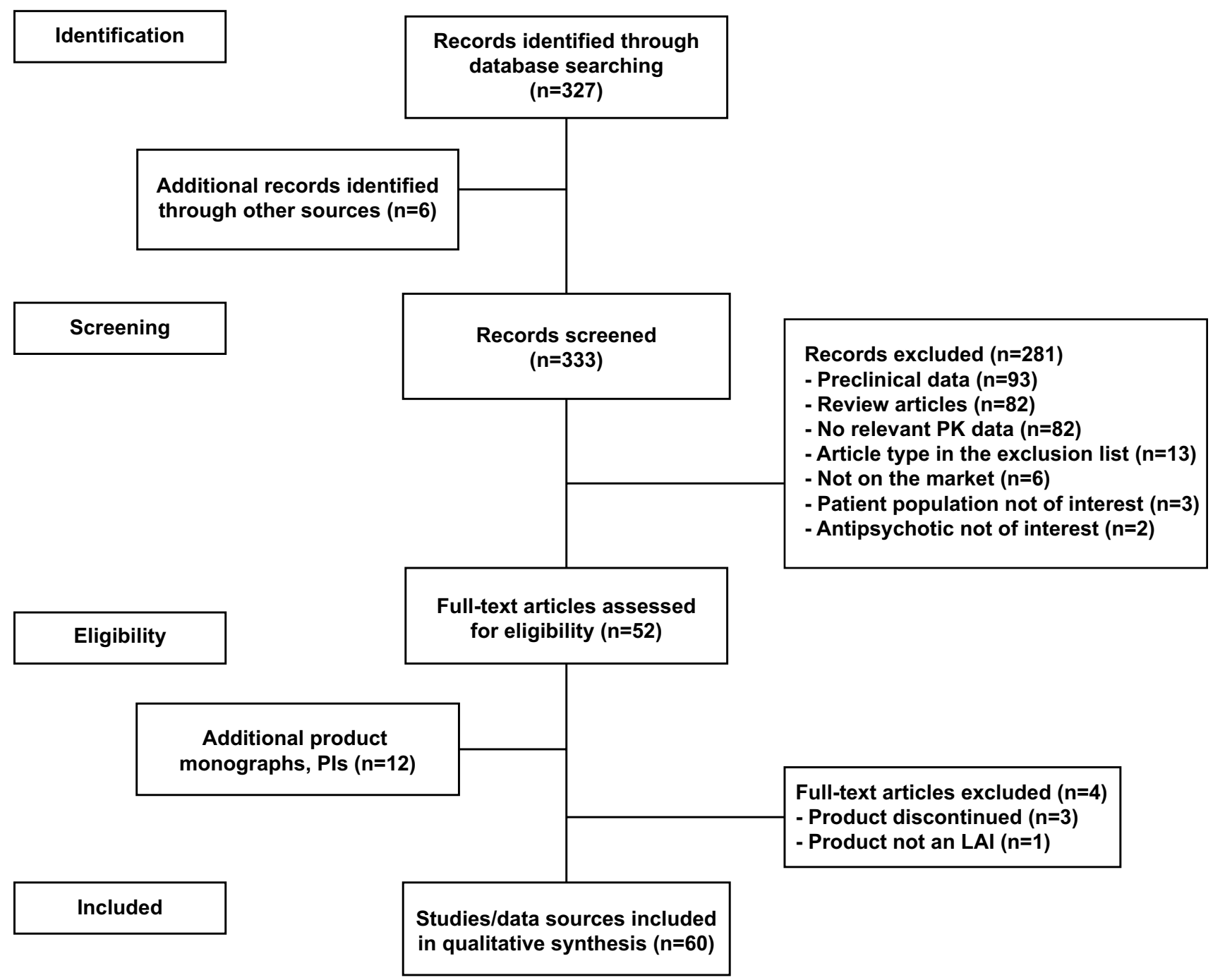

Fig. 3 PRISMA flow diagram. $L A I$ long-acting injectable, $P K$ pharmacokinetics, $P I$ package insert 
from commercial markets, and antipsychotics studied primarily in patients with diseases other than schizophrenia were also excluded from this review. One rater conducted the initial abstract screening, and all authors reviewed and agreed to the final selection of relevant abstracts. Full-text manuscripts were then obtained and analyzed. In addition,

Table 1 Formulation properties of long-acting injectable antipsychotics

\begin{tabular}{|c|c|c|c|}
\hline LAI & Formulation & Route & Storage/Preparation \\
\hline Flupentixol decanoate & Decanoate ester [45] & IM injection, gluteal [45] & $\begin{array}{l}\text { Storage: store between } 15 \text { and } 25^{\circ} \mathrm{C} \text {; } \\
\text { protect from light [45] } \\
\text { Preparation: Viscoleo, vegetable oil } \\
\text { [44] }\end{array}$ \\
\hline Fluphenazine decanoate & Decanoate ester [53] & IM injection, gluteal [49] & $\begin{array}{l}\text { Storage: do not store above } 25^{\circ} \mathrm{C} \text {; } \\
\text { do not refrigerate or freeze; protect } \\
\text { from light [49] } \\
\text { Preparation: sesame oil [60] }\end{array}$ \\
\hline Haloperidol decanoate & Decanoate ester [54] & IM injection, gluteal [54] & $\begin{array}{l}\text { Storage: store between } 15 \text { and } 30^{\circ} \mathrm{C} \text {; } \\
\text { do not refrigerate or freeze [113] } \\
\text { Preparation: sesame oil [54] }\end{array}$ \\
\hline Zuclopenthixol decanoate & Decanoate ester [59] & IM injection, gluteal [59] & $\begin{array}{l}\text { Storage: store between } 15 \text { and } 25^{\circ} \mathrm{C} \text {; } \\
\text { protect from light [59] } \\
\text { Preparation: Viscoleo, vegetable oil } \\
\text { [60] }\end{array}$ \\
\hline Aripiprazole monohydrate & Lyophilized powder [61] & IM injection, deltoid or gluteal [61] & $\begin{array}{l}\text { Storage (prefilled dual chamber } \\
\text { syringe): Store below } 30{ }^{\circ} \mathrm{C} \text {; do not } \\
\text { freeze; protect from light [61]. } \\
\text { Storage (vial): Store at } 25^{\circ} \mathrm{C}[61] \\
\text { Preparation: water [61] }\end{array}$ \\
\hline Aripiprazole lauroxil & Nonester [63] & $\begin{array}{l}\text { IM injection, deltoid (441 mg only) } \\
\text { or gluteal [67] }\end{array}$ & $\begin{array}{l}\text { Storage: store at room temperature } \\
\text { between } 20 \text { and } 25^{\circ} \mathrm{C}[67] \\
\text { Preparation: water [63] }\end{array}$ \\
\hline $\begin{array}{l}\text { Aripiprazole lauroxil NanoCrystal } \\
\text { Dispersion }\end{array}$ & LinkeRx ${ }^{\circledR}$ technology [69] & $\begin{array}{l}\text { IM injection } 675 \mathrm{mg} \text { deltoid or } \\
\text { gluteal with one } 30 \mathrm{mg} \text { oral dose } \\
\text { of aripiprazole [69] }\end{array}$ & $\begin{array}{l}\text { Storage: store at room temperature } \\
\text { between } 20 \text { and } 25^{\circ} \mathrm{C}[69] \\
\text { Preparation: water [69] }\end{array}$ \\
\hline Olanzapine pamoate & Salt (pamoate) [72] & IM injection, gluteal [72] & $\begin{array}{l}\text { Storage: store at room temperature } \\
\quad\left(\text { do not exceed } 30^{\circ} \mathrm{C}\right) \\
\text { Preparation: salt based }\end{array}$ \\
\hline Paliperidone palmitate once monthly & Ester (palmitate) [76] & IM injection, deltoid or gluteal [77] & $\begin{array}{l}\text { Storage: store at room temperature } \\
\left(25^{\circ} \mathrm{C}\right)[77] \\
\text { Preparation: water/nanosuspension } \\
{[76,78,114]}\end{array}$ \\
\hline $\begin{array}{l}\text { Paliperidone palmitate every } 3 \\
\text { months }\end{array}$ & Ester (palmitate) $[82,115]$ & IM injection, deltoid or gluteal [81] & $\begin{array}{l}\text { Storage: store at room temperature } \\
\text { between } 20 \text { and } 25^{\circ} \mathrm{C}[81] \\
\text { Preparation: water/nanosuspension } \\
\text { [81] }\end{array}$ \\
\hline Risperidone microspheres & Microspheres [84] & IM injection, deltoid or gluteal [84] & $\begin{array}{l}\text { Storage: store in refrigerator between } \\
\left.2 \text { and } 8{ }^{\circ} \mathrm{C} \text {; protect from light [ } 84\right] \\
\text { Preparation: water [85-88] (let warm } \\
\text { to room temperature before admin- } \\
\text { istration) }\end{array}$ \\
\hline Risperidone polymer & $\begin{array}{l}\text { Co-polymer; ATRIGEL }{ }^{\circledR} \\
\text { technology }[90-92,116]\end{array}$ & SC injection, abdomen [93] & $\begin{array}{l}\text { Storage: store in refrigerator between } \\
2 \text { and } 8{ }^{\circ} \mathrm{C} \text {; may be stored in its } \\
\text { unopened original packaging at } \\
\text { room temperature, } 20-25^{\circ} \mathrm{C} \text {, for up } \\
\text { to } 7 \text { days prior to administration; } \\
\text { after removal from the refrigerator, } \\
\text { use within } 7 \text { days or discard [93] } \\
\text { Preparation: water [90-92, 116] (let } \\
\text { warm to room temp before admin- } \\
\text { istration) }\end{array}$ \\
\hline
\end{tabular}

$I M$ intramuscular, $L A I$ long-acting injectable, $S C$ subcutaneous 
Table 2 Pharmacokinetic characteristics of long-acting injectable antipsychotics

\begin{tabular}{|c|c|c|c|}
\hline LAI & $t_{\max }$ & Apparent half-life & Contraindications and dosing adjustments \\
\hline Flupentixol decanoate & $\begin{array}{l}4-10 \text { days }[44] \\
4-7 \text { days }[45]\end{array}$ & $\begin{array}{l}35 \mathrm{~h} \text { (oral and IV) [44] } \\
21 \text { days (IM) [45] }\end{array}$ & $\begin{array}{l}\text { Contraindicated in patients with impaired liver or renal func- } \\
\text { tion [45] }\end{array}$ \\
\hline Fluphenazine decanoate & - & 7-10 days [49] & $\begin{array}{l}\text { Contraindicated in patients with renal insufficiency [49] } \\
\text { Concomitant administration of CYP2D6 substrates or inhibitors } \\
\text { may result in increased fluphenazine concentrations [49] }\end{array}$ \\
\hline Haloperidol decanoate & $3-9$ days $[39,54]$ & 21 days [54] & $\begin{array}{l}\text { Concomitant administration of substrates or inhibitors of } \\
\text { CYP3A4 or CYP2D6 may result in increased haloperidol } \\
\text { concentrations [54] } \\
\text { Concomitant administration with CYP3A4 inducers (e.g., } \\
\text { rifampin and carbamazepine) may require haloperidol } \\
\text { decanoate dose increases }[54,58]\end{array}$ \\
\hline Zuclopenthixol decanoate & 3-7 days $[59,60]$ & 19 days [59] & $\begin{array}{l}\text { Zuclopenthixol is primarily metabolized by CYP2D6 and } \\
\text { CYP3A4; concomitant use of CYP2D6 inhibitors (e.g., quini- } \\
\text { dine) can increase serum concentration of zuclopenthixol, and } \\
\text { concomitant use of CYP3A4 inducers (e.g., carbamazepine) } \\
\text { can decrease serum concentration of zuclopenthixol [59, 117] } \\
\text { Concomitant administration of CYP2D6 inhibitors may result } \\
\text { in decreased zuclopenthixol clearance [59] }\end{array}$ \\
\hline $\begin{array}{l}\text { Aripiprazole monohy- } \\
\text { drate }\end{array}$ & $\begin{array}{l}\text { Deltoid: } 4 \text { days }[61 \text {, } \\
\text { 62] } \\
\text { Gluteal: } 5-7 \text { days }[61 \text {, } \\
62]\end{array}$ & 29.9-46.5 days $[61]$ & $\begin{array}{l}\text { Adjust dose for known poor metabolizers of CYP2D6 and } \\
\text { known poor metabolizers of CYP2D6 taking concomitant } \\
\text { CYP3A4 inhibitors [61] } \\
\text { Reduce dose with concomitant administration of CYP2D6 or } \\
\text { CYP3A4 inhibitors for }>14 \text { days [61] } \\
\text { Avoid use with concomitant administration of CYP3A4 induc- } \\
\text { ers for }>14 \text { days [61] } \\
\text { Dosage adjustments are not recommended for patients with } \\
\text { concomitant administration of CYP3A4 or CYP2D6 inhibi- } \\
\text { tors and CYP3A4 inducers for }<14 \text { days [61] }\end{array}$ \\
\hline Aripiprazole lauroxil & 41 days $[63]$ & $\begin{array}{l}441 \text { mg q4w: } 57.2 \text { days } \\
\text { [66, 67] } \\
882 \text { mg q6w: } 55.1 \text { days } \\
\text { [66, 67] } \\
1064 \text { mg q8w: } 53.9 \text { days } \\
{[66,67]}\end{array}$ & $\begin{array}{l}\text { Reduce dose with concomitant administration of strong } \\
\text { CYP3A4 inhibitors and for known CYP2D6 poor metaboliz- } \\
\text { ers taking concomitant strong CYP3A4 inhibitor; no dosage } \\
\text { adjustment is necessary in patients taking the } 441 \mathrm{mg} \text { dose } \\
\text { [67] } \\
\text { Reduce dose with concomitant administration of strong } \\
\text { CYP2D6 inhibitors; no dosage adjustment is necessary in } \\
\text { patients taking the } 441 \mathrm{mg} \text { dose [67] } \\
\text { Avoid use of the } 662 \mathrm{mg}, 882 \mathrm{mg} \text {, or } 1064 \mathrm{mg} \text { dose with } \\
\text { concomitant administration of both strong CYP3A4 inhibi- } \\
\text { tors and strong CYP2D6 inhibitors; no dosage adjustment is } \\
\text { necessary in patients taking the } 441 \mathrm{mg} \text { dose [67] } \\
\text { Increase } 441 \mathrm{mg} \text { dose to } 662 \mathrm{mg} \text { with concomitant administra- } \\
\text { tion of CYP3A4 inducers; no dosage adjustment is necessary } \\
\text { in patients taking the } 662 \mathrm{mg}, 882 \mathrm{mg} \text {, or } 1064 \mathrm{mg} \text { dose [67] }\end{array}$ \\
\hline $\begin{array}{l}\text { Aripiprazole lau- } \\
\text { roxil NanoCrystal } \\
\text { Dispersion }\end{array}$ & $\begin{array}{l}27 \text { (range 16-35) days } \\
\text { [69] } \\
4 \text { days with a concom- } \\
\text { itant } 30 \mathrm{mg} \text { oral dose } \\
\text { of aripiprazole [69] }\end{array}$ & 15-18 days [69] & $\begin{array}{l}\text { Aripiprazole lauroxil NanoCrystal }{ }^{\circledR} \text { Dispersion is available } \\
\text { only at a single strength as a single-dose prefilled syringe; } \\
\text { dosage adjustments are not possible. Therefore, avoid use in } \\
\text { patients who are known poor metabolizers of CYP2D6 or } \\
\text { taking strong CYP3A4 inhibitors, strong CYP2D6 inhibitors, } \\
\text { or strong CYP3A4 inducers [69] }\end{array}$ \\
\hline Olanzapine pamoate & $2-6$ days $[70,71]$ & $\sim 30$ days [72] & $\begin{array}{l}\text { The recommended starting dose is } 150 \mathrm{mg} / 4 \text { weeks for patients } \\
\text { who exhibit factors that may result in slower metabolism of } \\
\text { olanzapine (e.g., nonsmoking females, patients aged }>65 \\
\text { years) [72] }\end{array}$ \\
\hline
\end{tabular}


Table 2 (continued)

\begin{tabular}{|c|c|c|c|}
\hline LAI & $t_{\max }$ & Apparent half-life & Contraindications and dosing adjustments \\
\hline $\begin{array}{l}\text { Paliperidone palmitate } \\
\text { once monthly }\end{array}$ & 13 days [77] & 25-49 days [77] & $\begin{array}{l}\text { For patients with mild renal impairment (creatinine clearance } \\
\geq 50 \text { to }<80 \mathrm{~mL} / \mathrm{min} \text { ), initiate the } 156 \mathrm{mg} \text { dose on treatment } \\
\text { day } 1 \text { and } 117 \mathrm{mg} 1 \text { week later, both in the deltoid muscle; } \\
\text { thereafter, administer monthly injections of } 78 \mathrm{mg} \text { in either } \\
\text { the deltoid or the gluteal muscle [77] } \\
\text { Not recommended in patients with moderate or severe renal } \\
\text { impairment (creatinine clearance }<50 \mathrm{~mL} / \mathrm{min} \text { ) [77] } \\
\text { Avoid use with concomitant administration of strong CYP3A4 } \\
\text { and/or P-gp inducers [77] }\end{array}$ \\
\hline $\begin{array}{l}\text { Paliperidone palmitate } \\
\text { every } 3 \text { months }\end{array}$ & 30-33 days [81] & $\begin{array}{l}\text { Deltoid: } 84-95 \text { days [ } 81] \\
\text { Gluteal: } 118-139 \text { days } \\
\text { [81] }\end{array}$ & $\begin{array}{l}\text { For patients with mild renal impairment (creatinine clearance } \\
\geq 50 \text { to }<80 \mathrm{~mL} / \mathrm{min} \text { ), adjust dosage and stabilize patient } \\
\text { using PP1M, then transition to PP3M [81] } \\
\text { Not recommended in patients with moderate or severe renal } \\
\text { impairment (creatinine clearance }<50 \mathrm{~mL} / \mathrm{min} \text { ) [81] } \\
\text { Avoid use with concomitant administration of CYP3A4 and/or } \\
\text { P-gp inducers during the 3-month interval [81] }\end{array}$ \\
\hline Risperidone microspheres & $\sim 30$ days $[86]$ & $3-6$ days $[84]$ & $\begin{array}{l}\text { Titrate doses of oral risperidone before initiating risperidone } \\
\text { microspheres in patients with renal or hepatic impairment } \\
\text { [84] } \\
\text { Monitor and adjust dose of risperidone microspheres in patients } \\
\text { receiving concomitant administration of CYP3A4 inducers } \\
\text { [84] } \\
\text { Reevaluate dose of risperidone microspheres when concomitant } \\
\text { fluoxetine or paroxetine (CYP2D6 inhibitor) is initiated or } \\
\text { discontinued; may consider lower dose of risperidone micro- } \\
\text { spheres 2-4 weeks before the planned initiation of fluoxetine } \\
\text { or paroxetine [84] }\end{array}$ \\
\hline Risperidone polymer & $\begin{array}{l}\text { Risperidone: } 4-6 \mathrm{~h} \\
\text { [93] }\end{array}$ & $\begin{array}{l}\text { Risperidone: } 9-11 \text { days } \\
\text { [93] } \\
\text { 9-hydroxyrisperidone: 8-9 } \\
\text { days [93] } \\
\text { Total active moiety: 8-9 } \\
\text { days [93] }\end{array}$ & $\begin{array}{l}\text { May consider lowest dose of RLAI-polymer 2-4 weeks before } \\
\text { the planned start of a strong CYP2D6 inhibitor (fluoxetine or } \\
\text { paroxetine) [93] } \\
\text { Continue treatment in patients receiving } 90 \mathrm{mg} \text { of RLAI-poly- } \\
\text { mer when initiating a strong CYP2D6 inhibitor (fluoxetine or } \\
\text { paroxetine) [93] } \\
\text { May consider increasing the } 90 \mathrm{mg} \text { dose of RLAI-polymer to } \\
120 \mathrm{mg} \text { with initiation of strong CYP3A4 inducers [93] } \\
\text { May consider an additional oral risperidone therapy in patients } \\
\text { receiving } 120 \mathrm{mg} \text { of RLAI-polymer [93] }\end{array}$ \\
\hline
\end{tabular}

CYP cytochrome P450, IM intramuscular, IV intravenous, LAI long-acting injectable, $P$-gp P-glycoprotein, $P P 1 M$ paliperidone palmitate once monthly, $P P 3 M$ paliperidone palmitate every 3 months, $q x w$ every $\mathrm{x}$ weeks, $R L A I$ risperidone long-acting injectable, $t_{\max }$ time to maximum concentration

pharmacokinetic data from the package inserts and product monographs of all commercially available LAI antipsychotics were examined. On 11 September 2020, a second literature search was performed to find articles published after 18 October 2018. Two individual raters manually screened the abstracts, and all authors reviewed and agreed to the final selection of relevant abstracts. Updated package inserts and product monographs, and published manuscripts relevant to the review but not captured by the updated literature search, were also included as applicable.

The initial PubMed search terms returned 327 English language articles. One article of interest [37] was examined further to identify additional relevant references [38, 39], and other articles of interest [40-43] that did not meet the original search criteria were included; in total, six additional references were selected for inclusion in the current review (Fig. 3). After manual screening, a total of 52 abstracts were identified as presenting relevant pharmacokinetic data from LAI antipsychotics. In addition, data were also extracted from 12 product package inserts and/or product monographs. The second literature search identified three relevant abstracts. The formulation properties, pharmacokinetic characteristics, and administration details of each first-generation and second-generation LAI antipsychotic are summarized in Tables 1, 2, and 3. Table 2 in the ESM summarizes each relevant published manuscript included in this analysis. 


\section{First-Generation Long-Acting Injectable (LAI) Antipsychotics}

\subsection{Flupentixol Decanoate}

Flupentixol is a thioxanthene antipsychotic. The LAI preparation is formulated with $\operatorname{cis}(\mathrm{Z})$-flupenthixol isomer (the active enantiomer) using a decanoate ester in the coconutderived oil vehicle, Viscoleo [44]. Flupentixol metabolites are not pharmacologically active $[45,46]$. While the ester is rapidly hydrolyzed, releasing the active compound, the depot properties depend on the slow release of the ester from the oil vehicle [44]. Flupentixol decanoate is administered via intramuscular gluteal injection [45]. The mean apparent half-life was estimated at 17.3 days, based on concentration data at steady state obtained at days 14, 21, and 28 [44]. However, wide variability in apparent half-lives has been reported (5.3-112.6 days), owing to uneven release of the ester from the oil. Peak plasma concentrations of flupentixol decanoate are achieved 4-10 days after injection, indicating a relatively slow absorption compared with the $t_{\max }$ of oral flupentixol (4 h) [44]. Steady-state levels are attained after approximately 3 months [45]. The initial and maintenance dose of flupentixol decanoate for most patients is $20-40 \mathrm{mg}$ every 2-3 weeks [45]. Although the recommended dose range of flupentixol decanoate is broad, recent evidence suggests that doses close to or below the minimum recommended dose (as low as $10 \mathrm{mg}$ every 2 weeks) are effective [47]. Flupentixol is predominantly metabolized by sulfoxidation and lacks interactions associated with CYP inducers or inhibitors [45]. No guidance is provided about action that should be taken if doses of flupentixol decanoate or other first-generation LAI antipsychotics are missed. Oral flupentixol $10 \mathrm{mg}$ per day was estimated to be equivalent to intramuscular flupentixol decanoate $40 \mathrm{mg}$ every 2 weeks [44].

\subsection{Fluphenazine Decanoate}

Fluphenazine decanoate is the only commercially available LAI formulation of the phenothiazine fluphenazine [48, 49]. The LAI formulation contains esters dissolved in sesame oil; fluphenazine decanoate is "preferably" administered as an intramuscular gluteal injection, although it may also be administered subcutaneously [49, 50]. Fluphenazine plasma concentrations are similar regardless of the injection site (buttock vs. thigh area), whether the injection site is massaged (vs. not), and whether the injection site undergoes muscular exercise (vs. not) [51]. After intramuscular gluteal administration, peak plasma concentrations of fluphenazine decanoate occur within $24 \mathrm{~h}$, and the apparent half-life is $\sim 7-10$ days, determined by the rate of ester release from the depot $[42,49]$. Fluphenazine is extensively metabolized, undergoing "first-pass" metabolism by the liver, and is excreted in both urine and feces [49]. Other phenothiazines cross the blood-brain barrier, cross the placenta easily, and cannot be removed by dialysis [49]. The recommended maintenance dose of fluphenazine decanoate is $12.5-25 \mathrm{mg}$ every 2-3 weeks for most patients [49]; however, maintenance doses as low as $1.25-5 \mathrm{mg}$ every 2 weeks have been shown to be effective in preventing relapse [52]. A $25 \mathrm{mg}$ (1 $\mathrm{mL}$ ) injection of fluphenazine decanoate every 3 weeks is equivalent to a $20 \mathrm{mg}$ oral dose of fluphenazine hydrochloride daily [53].

\subsection{Haloperidol Decanoate}

The LAI formulation of the butyrophenone haloperidol is available as a decanoate ester in a sesame oil vehicle and is administered via intramuscular gluteal or deltoid injection $[37,54,55]$. After injection, haloperidol decanoate is slowly released into the bloodstream and immediately hydrolyzed, resulting in active haloperidol [38]. Peak plasma concentrations are apparent between 3 and 9 days, with an elimination half-life of approximately 3 weeks $[39,54]$. Steady-state levels are achieved after the third injection, or after 3 months, which is a period approximately four to five times the apparent half-life [39]. Haloperidol concentrations achieved with haloperidol decanoate are comparable to 10-20 times the previous daily dose of oral haloperidol equivalents, and an initial dose of 10-20 times the previous daily oral dose is recommended [54]. Because of the slow dose titration and extended time to reach steady state, which are characteristic of older LAIs, initial oral antipsychotic supplementation may be required [56]. Haloperidol decanoate can be supplemented with oral haloperidol for 6 weeks when transitioning to the LAI formulation [57]. The maintenance dose is usually $10-15$ times the previous daily oral dose, depending on clinical response [54]. The recommended dosing interval is every 4 weeks [38]. Haloperidol is a substrate of CYP3A4 and CYP2D6, and concomitant administration with inhibitors of these enzymes increases the concentrations of haloperidol and may require dose reductions $[54,58]$. By contrast, concomitant administration with CYP3A4 inducers, such as rifampin and carbamazepine, may require haloperidol decanoate dose increases [54, 58].

\subsection{Zuclopenthixol Decanoate}

Zuclopenthixol, a thioxanthene antipsychotic, is the cisisomer of clopenthixol. Zuclopenthixol decanoate is formulated by esterification and dissolution in the coconut-derived oil vehicle, Viscoleo [59]. This formulation is administered intramuscularly, and the drug diffuses slowly from the oil depot and hydrolyzes rapidly into the active moiety, zuclopenthixol $[59,60]$. Maximum serum concentrations occur 


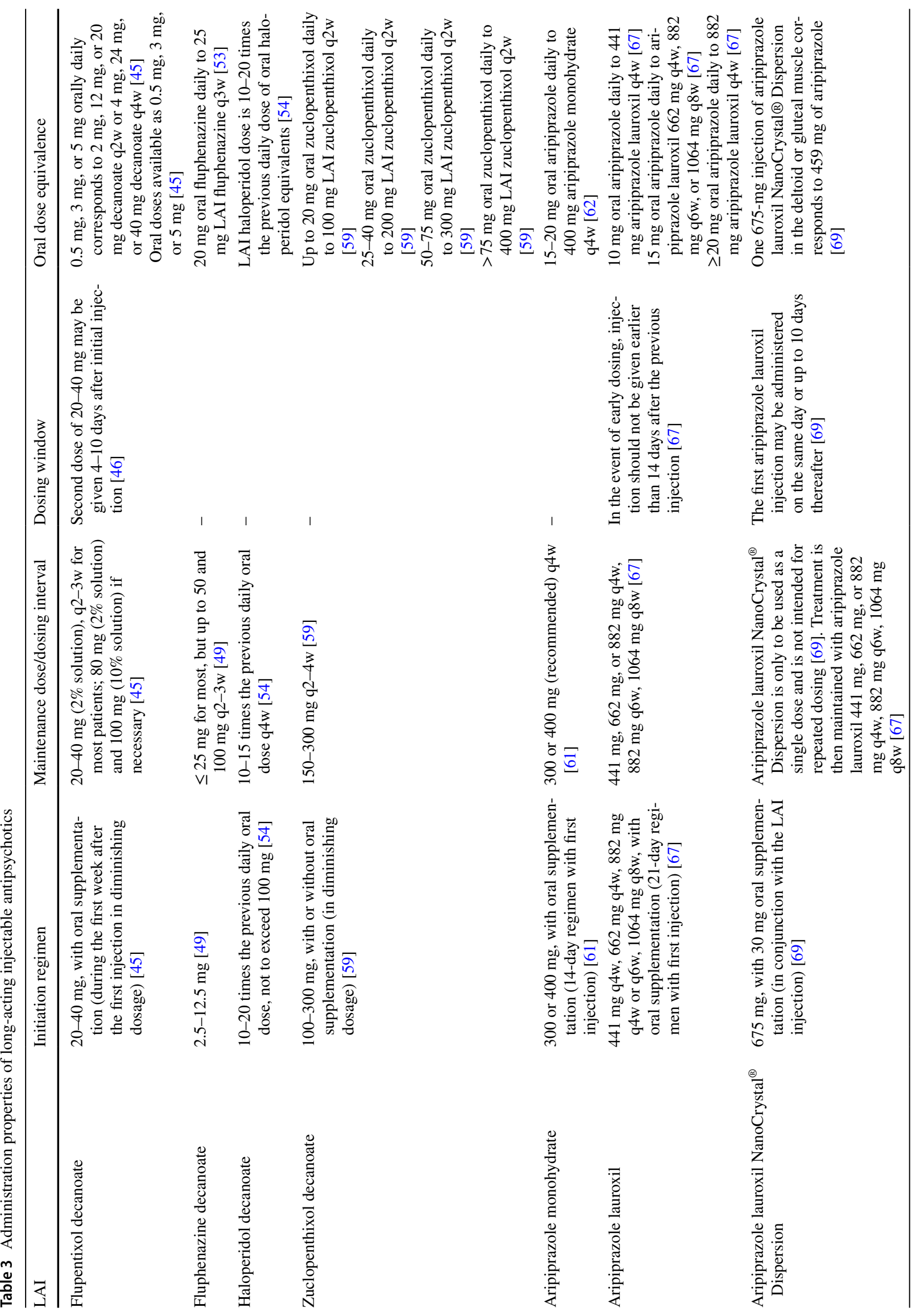




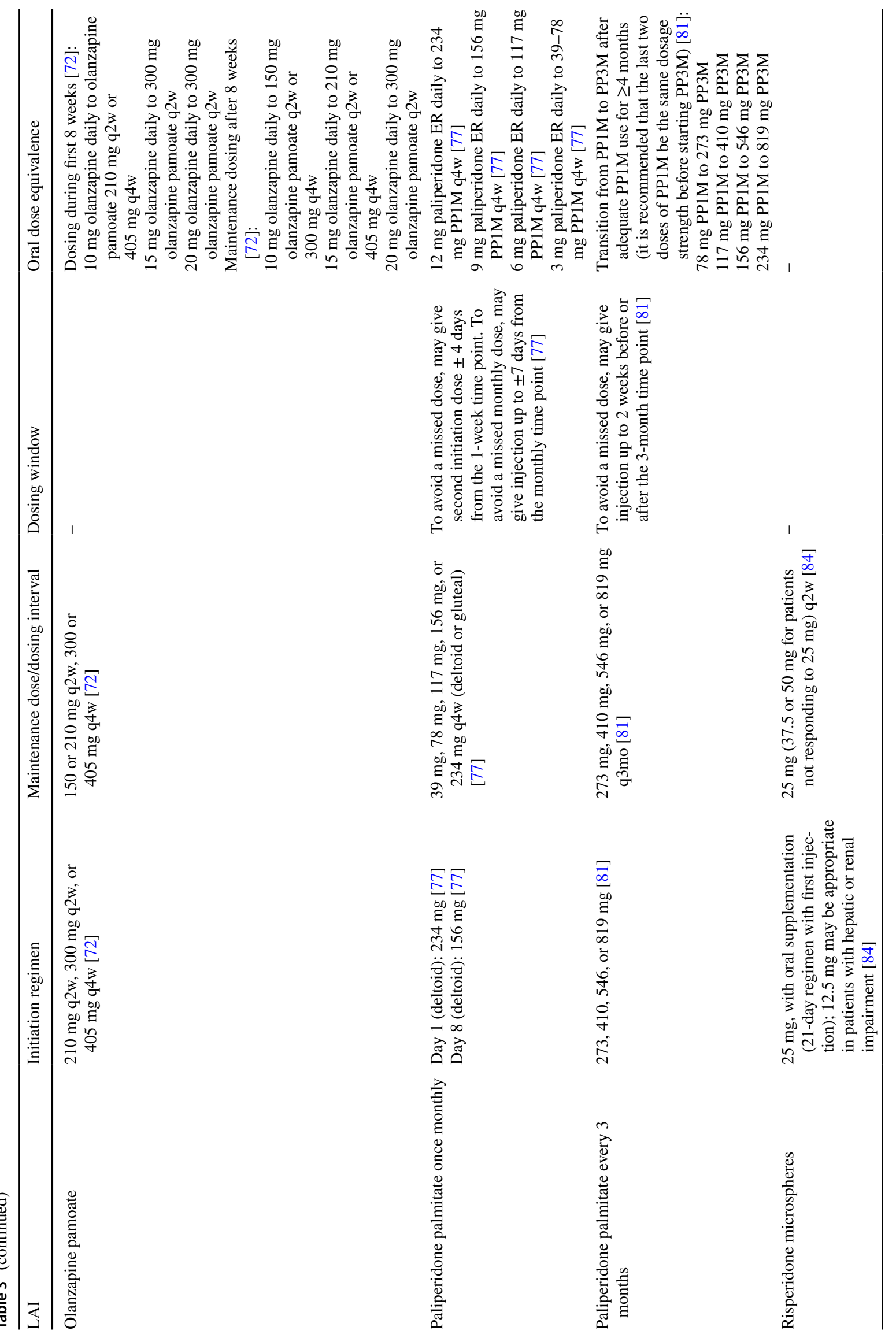


in 3-7 days, and the elimination half-life is 19 days [59, 60]. Zuclopenthixol is primarily metabolized by CYP2D6 and CYP3A4; concomitant use of CYP2D6 inhibitors (e.g., quinidine) can increase serum zuclopenthixol concentration, whereas concomitant use of CYP3A4 inducers (e.g., carbamazepine) can decrease serum zuclopenthixol concentrations [59]. Zuclopenthixol decanoate is meant for maintenance treatment after patients have been stabilized with an oral antipsychotic or other short-acting medications; no specific initiation regimen is recommended [59]. The typical maintenance dose is $150-300 \mathrm{mg}$ every $2-4$ weeks. Supplementation with an oral antipsychotic may be required in periods of diminished dosage. Dose equivalences when switching from zuclopenthixol tablets to zuclopenthixol decanoate range from 20 to $75 \mathrm{mg}$ daily (tablet) to 100 to $400 \mathrm{mg}$ every 2 weeks (intramuscularly) [59].

\section{Second-Generation LAI Antipsychotics}

\subsection{Aripiprazole Monohydrate}

Aripiprazole monohydrate, a once-monthly formulation, is distributed as a lyophilized powder ( $300 \mathrm{or} 400 \mathrm{mg}$ ) to be mixed into an aqueous suspension from vials and a dualchamber prefilled syringe [61]. Aripiprazole monohydrate is administered via intramuscular injection in either the deltoid or the gluteal regions [61, 62]. Aripiprazole monohydrate lyophilized powder is dissolved in sterile water immediately prior to injection and is slowly absorbed into systemic circulation because of its low solubility [61]. The activity of aripiprazole monohydrate is primarily due to the parent drug, aripiprazole, and to a lesser extent, its major metabolite, dehydro-aripiprazole, which represents about $29 \%$ of the parent drug exposure in plasma [61]. Median time to peak plasma concentration occurs within 4 days following multiple deltoid injections and 5-7 days following multiple gluteal injections, and apparent half-life varies from 29.9 to 46.5 days [61]. Steady-state levels are typically achieved by the fourth dose with either deltoid or gluteal injections [61]. Metabolism is primarily through the liver via CYP2D6 and CYP3A4 [61]. Dosing reductions are recommended for patients who are poor metabolizers of CYP2D6 and in patients taking CYP3A4 or CYP2D6 inhibitors for more than 14 days. Concomitant use with CYP3A4 inducers for more than 14 days should be avoided [61]. Aripiprazole monohydrate is administered at a recommended dose of 400 $\mathrm{mg}$, with administration of oral aripiprazole for 14 days after the first injection. The dose may be reduced to $300 \mathrm{mg}$ if side effects occur [61]. Missed or late doses may require oral aripiprazole supplementation, depending on the duration of time between injections [61]. Aripiprazole concentrations achieved by aripiprazole monohydrate $400 \mathrm{mg}$ once monthly 
are comparable to those with oral aripiprazole $15-20 \mathrm{mg}$ daily [62].

\subsection{Aripiprazole Lauroxil}

Aripiprazole lauroxil, another long-acting formulation of aripiprazole, consists of the nonester prodrug $N$-lauroyloxymethyl aripiprazole [63]. Aripiprazole lauroxil is supplied as an aqueous suspension for intramuscular injection in either the deltoid (lowest dose only; $441 \mathrm{mg}$ ) or gluteal regions (any dose) [63]. Doses of aripiprazole lauroxil reflect the amount of covalently bonded molecule in the formulation, as opposed to the equivalent amount of active agent, reflecting recent regulatory guidance $[64,65]$. Once injected, aripiprazole lauroxil slowly dissolves into the systemic circulation, where it is first converted to $N$-hydroxymethyl aripiprazole and lauric acid; the $N$-hydroxymethyl group is subsequently removed by rapid hydrolysis, releasing active aripiprazole [63]. Peak plasma concentrations are attained approximately 41 days after a single administration [63]. Using data after $t_{\max }$ (41 days) estimates the elimination half-life of aripiprazole lauroxil at 53.9-57.2 days [66]. Steady-state levels are achieved 4 months following treatment initiation [67]. As aripiprazole is the same active ingredient for both aripiprazole monohydrate and aripiprazole lauroxil, the same caveats apply for CYP450-related dosing adjustments as well as for poor metabolizers of CYP2D6 and patients taking CYP3A4 or CYP2D6 inhibitors. Aripiprazole lauroxil is administered every 4 weeks ( $441 \mathrm{mg}, 662 \mathrm{mg}$, or $882 \mathrm{mg}$ ), every 6 weeks $(882 \mathrm{mg})$, or every 8 weeks $(1064 \mathrm{mg})$. When aripiprazole lauroxil was first approved, oral supplementation with aripiprazole was recommended for 21 days following initiation $[63,68]$. An intramuscular injectable nanocrystalline milled dispersion of aripiprazole lauroxil $\left(\mathrm{AL}_{\mathrm{NCD}}, 675 \mathrm{mg}\right)$ is available as a component of a 1-day initiation regimen that includes $30 \mathrm{mg}$ of oral aripiprazole [41, 69]. The targeted maintenance dose of aripiprazole lauroxil may be administered on the same day or up to 10 days after administration of $\mathrm{AL}_{\mathrm{NCD}}+$ oral aripiprazole [69]. The $\mathrm{AL}_{\mathrm{NCD}}$ regimen may also be used to reinitiate treatment after missed doses of aripiprazole lauroxil [69]. Patients who miss a dose should receive the next injection as soon as possible; depending on the dose level and length of time since missing the dose, oral supplementation or an additional dose of $\mathrm{AL}_{\mathrm{NCD}}$ would be required. Dose equivalencies with the oral formulation are shown in Table 3.

Salzman et al. [40] compared plasma concentrations of aripiprazole between once-monthly dosing of aripiprazole monohydrate $400 \mathrm{mg}$ and aripiprazole lauroxil $882 \mathrm{mg}$. Although the aripiprazole lauroxil $882 \mathrm{mg}$ injection contains aripiprazole $600 \mathrm{mg}$ whereas aripiprazole monohydrate $400 \mathrm{mg}$ contains aripiprazole $400 \mathrm{mg}$, median steady-state plasma concentrations were similar, raising uncertainty around the dose equivalence data. Thus, plasma concentrations from different formulations may reflect not just the dose administered but the absorption of the drug from the depot aripiprazole [40]. However, these data should be interpreted with caution, as the data inputs from different time points and different steady-state concentrations (average vs. minimum) were compared.

\subsection{Olanzapine Pamoate}

Olanzapine pamoate is a long-acting formulation of olanzapine, comprising a low-solubility salt of pamoic acid and olanzapine, suspended in an aqueous solution for intramuscular gluteal injection [70, 71]. After intramuscular injection, the salt slowly dissolves in intramuscular fluid into olanzapine (free base), pamoic acid, and other acids and bases. If the salt comes into contact with the blood, possibly from a nicked blood vessel during administration, the salt rapidly dissolves within minutes to hours after injection of the drug, resulting in supratherapeutic concentrations [70]. In these cases, patients may experience signs and symptoms consistent with olanzapine overdose, known as post-injection delirium/sedation syndrome (PDSS); the risk of PDSS, noted in a boxed warning in the prescribing information, requires monitoring for at least $3 \mathrm{~h}$ after each injection [70, 72]. Plasma concentrations obtained after administration are proportional to the dose of olanzapine pamoate administered [71]. Peak plasma concentrations appear after 2-6 days [70, 71], and the apparent half-life is 30 days [70]. Steady-state levels are achieved in approximately 3 months when switching to olanzapine pamoate from oral olanzapine [72]. Direct glucuronidation and CYP450-mediated oxidation are the primary metabolic pathways for olanzapine. In vitro studies suggest that CYP1A2 and CYP2D6, and the flavin-containing monooxygenase system are involved in olanzapine oxidation. Although CYP2D6 is involved in the metabolism of olanzapine, clearance is not reduced in patients who are deficient in CYP2D6 [72]. Initiation doses range from $210 \mathrm{mg}$ every 2 weeks or $405 \mathrm{mg}$ every 4 weeks (corresponding to $10 \mathrm{mg}$ daily oral olanzapine) to $300 \mathrm{mg}$ every 2 weeks (corresponding to 15 or $20 \mathrm{mg}$ daily oral olanzapine) [72]. Although plasma concentrations of olanzapine can be lower after the first dose of olanzapine pamoate than those maintained by a corresponding oral dose, the concentrations achieved by the LAI dose are in the therapeutically effective range, suggesting that oral supplementation is not needed during LAI initiation [73]. No information is provided in the prescribing information regarding missed doses [72]. Oral dose equivalents for the $150 \mathrm{mg}$ and $300 \mathrm{mg}$ doses given every 2 weeks are 10 and $20 \mathrm{mg}$ daily, respectively [72]. 


\subsection{Paliperidone Palmitate Once Monthly}

Paliperidone palmitate is the long-acting esterified formulation of paliperidone that is available in formulations for administration once monthly (PP1M) and once every 3 months (PP3M) [74, 75]. The LAI formulations of paliperidone are delivered as aqueous nanoparticle suspensions [76]. Paliperidone palmitate is nearly insoluble in water; therefore, it dissolves slowly at the intramuscular injection site (either deltoid or gluteal), and is rapidly hydrolyzed to release paliperidone, the active ingredient (and the major metabolite of risperidone) [77, 78]. Peak plasma concentrations of PP1M are achieved at a median of 13 days after a single injection [76]. For PP1M, the observed apparent half-life of 25-49 days allows for once-monthly administration [76]. Paliperidone is primarily renally cleared and not extensively metabolized in the liver; $59 \%$ of a single dose is excreted in the urine unchanged [43,77]. Therefore, paliperidone has low potential for drug-drug interactions, and the CYP2D6 genotype should not affect serum concentrations [79]. Impairments or alterations in renal function can necessitate dosing adjustments [77]. Use of paliperidone with concomitant administration of strong CYP3A4 and/or $\mathrm{P}$-gp inducers should be avoided, if possible [77]. Moreover, paliperidone dose reductions may be necessary when coadministered with inhibitors of P-gp; P-gp efflux transporters are located in the kidney and other tissues and are responsible for exporting exogenous substances for elimination [23]. The recommended PP1M initiation dosing regimen consists of an injection of $234 \mathrm{mg}$ on day 1 and $156 \mathrm{mg}$ on day $8 \pm$ 4 days; both doses are administered in the deltoid muscle because of its higher vascularity than the gluteal muscle [75, 77]. The two-step initiation regimen for PP1M enables the drug to be absorbed from two separate sites, resulting in rapid therapeutically effective plasma concentrations without the need for oral supplementation. The half-life increases as the dose increases because of flip-flop kinetics, whereby the half-life is dependent on the absorption rate constant, which in turn is dependent on the injection volume [78]. As injection volume (and hence dose) increases, the absorption rate constant decreases, leading to an increase in half-life [78]. Steady state is achieved $8-9$ months after the initial injection (with the $234 \mathrm{mg}$ dose) $[78,80]$. The recommended initial monthly maintenance dose is $117 \mathrm{mg}$ (injected into the deltoid or gluteal regions), although some patients can benefit from maintenance dose adjustments ranging from 39 to $234 \mathrm{mg}$, with an allowable window of \pm 7 days to provide scheduling flexibility $[75,77]$. Similar to aripiprazole lauroxil, doses of the paliperidone palmitate formulations reflect the amount of covalently bonded molecule. A study of dose proportionality between maintenance injections of PP1M in the deltoid or gluteal muscles found that geometric mean amount absorbed, or AUC from time 0 to infinity
$\left(\mathrm{AUC}_{\infty}\right)$, increased proportionally with doses regardless of injection site, indicating that maintenance doses of PP1M can be injected into either the deltoid or the gluteal muscle [76]. In case of a missed maintenance dose $>6$ weeks and $\leq 6$ months after the last injection, two injections should be administered 1 week apart, followed by resumption of the previous maintenance dose, in the deltoid or gluteal muscle, 1 month after the second injection. For a missed maintenance dose $>6$ months since the last dose, the initiation regimen should be repeated [77]. Dose equivalence with paliperidone extended-release daily oral tablets is shown in Table 3.

\subsection{Paliperidone Palmitate Once Every 3 Months}

The PP3M formulation uses the same nanoparticle aqueous suspension technology as PP1M, only with an increased particle size and double the concentration with dose strengths of $273 \mathrm{mg}, 410 \mathrm{mg}, 546 \mathrm{mg}$, and $819 \mathrm{mg}$ of PP3M injected into the deltoid or gluteal muscles [81]. Compared with PP1M, the larger particle size (and therefore lower surface area to volume ratio) in PP3M further extends the sustained release of paliperidone, allowing for dosing once every 3 months [82]. Following a single dose of PP3M, peak plasma concentrations are obtained from 30 to 33 days, and the apparent half-life ranges from 84 to 95 days when administered into the deltoid muscle and from 118 to 139 days when administered into the gluteal muscle [81]. PP3M can be administered after patients have been adequately treated with PP1M for at least 4 months, provided that the last two doses are the same dosage strength [81]. The rationale for this approach is twofold. First, after a minimum of 4 months, PP1M will approach steady-state equilibrium, allowing a more robust assessment of the optimal dosage strength for patients. Therefore, clinicians may prefer to observe patients for longer than the recommended minimum in patients who are receiving higher doses or dose increases while on PP1M [83]. Ensuring that patients receive at least two doses of PP1M at the same strength confirms dose optimization and will eliminate the need for titration of PP3M, which would be challenging given the likelihood that steady state would occur 15 months after the last dosing change. The doses of PP3M (deltoid or gluteal) should be 3.5 times the corresponding stable prior PP1M dosage [81]. A window of \pm 2 weeks around the scheduled dosing is allowed to help avoid missing a dose and provides flexibility in dosing. If a dose is missed between 3.5 and $\leq 4$ months after the previous dose, the prior PP3M dosage should be administered, and the every-3-month schedule should follow this dosing. If a dose is missed $>4$ months and $\leq 9$ months since the time of the previous dose, a PP1M initiation regimen should be administered with dosing based upon the current PP3M dosing. If a dose is missed $>9$ months since the last injection, 
a PP1M initiation regimen should be administered, and PP3M can be resumed after the patient has been adequately treated with PP1M for $\geq 4$ months [81]. Similar to PP1M, PP3M is not extensively metabolized by the liver and has low potential for drug-drug interactions but does require dosing adjustments for decreased renal function [77, 81].

\subsection{Risperidone Microspheres}

The risperidone long-acting injection microspheres (RLAIMS) formulation was the first second-generation LAI developed, formulated as an aqueous suspension of microspheres of risperidone micro-encapsulated in 7525 polylactide-coglycolide [84-86]. The RLAI-MS formulation exhibits linear pharmacokinetics [85, 86] (Fig. 2 in the ESM). The main release of risperidone into systemic circulation begins 3 weeks after injection, and most active drug is released from weeks 4 to 6 [85, 87]. RLAI-MS formulation is administered via intramuscular injection in either the deltoid or the gluteal regions. Deltoid and gluteal injections have been shown to be bioequivalent in terms of peak and total plasma exposure, and both injection sites exhibited dose-proportional pharmacokinetics [86]. Administration of RLAI-MS every 2 weeks provides peak plasma concentration levels at approximately 4 weeks and a terminal apparent half-life of 3-6 days [88]. Steady-state concentrations are achieved after approximately four injections or 8 weeks [84]. Although a slow rate of absorption is the rate-limiting step in defining apparent half-life and time to steady state for most LAIs, this is not the case for RLAI-MS, which exhibits a triphasic release profile. During the initial "burst" phase after intramuscular injection, a small initial release of drug $(<1 \%$ of the dose) occurs, which is then followed by a 3-week "lag" phase of minimal drug release [89]. The main release of the drug starts from 3 weeks onward, is maintained from 4 to 6 weeks, and subsides by 7 weeks following intramuscular injection [84]. The half-life described in the monograph represents the rate of absorption after the burst and lag phases, which limits the clinical significance of this parameter [89]. Oral supplementation with risperidone or another oral antipsychotic is recommended for the first 3 weeks after initiation $[85,86]$. The recommended maintenance dose is 25 mg every 2 weeks; some patients who do not respond to the $25 \mathrm{mg}$ dose may benefit from a dose increase to $37.5 \mathrm{mg}$ or $50 \mathrm{mg}$ every 2 weeks. No information is provided in the prescribing information regarding action required for missed or late doses [84]. The main metabolic pathway for risperidone is via hepatic hydroxylation to 9-hydroxyrisperidone, or paliperidone, by CYP2D6. Concomitant administration of carbamazepine and other CYP3A4 inducers with risperidone might necessitate dose adjustments, as plasma concentrations of risperidone and 9-hydroxyrisperidone would be expected to decrease [84].

\subsection{Risperidone 2-Syringe Mixing System Suspension Polymer}

A more recent formulation of LAI risperidone provides sustained release of risperidone once monthly via abdominal subcutaneous injection (RLAI-polymer) [90, 91]. This formulation of risperidone uses the biodegradable polymer ATRIGEL ${ }^{\circledR}$ delivery system, whereby risperidone is dissolved and suspended in a polymer that solidifies upon contact with tissue fluids [92]. The biodegradable implant then delivers risperidone in a controlled fashion [91]. The apparent half-life of risperidone ranges between 9 and 11 days [93]. For both 9-hydroxyrisperidone and the total active moiety, the apparent half-life is 8-9 days. A single dose of RLAI-polymer demonstrates two absorption peaks of plasma risperidone: $4-6 \mathrm{~h}$ postdose during the in situ depot formation process, and 10-14 days postdose after the slow depot release [93]. Therefore, no oral supplementation is needed. The recommended initiation dose of RLAI-polymer is either 90 or $120 \mathrm{mg}$ once monthly [93]. Steady-state levels are achieved by the end of the second injection of LAI risperidone [93]. The metabolic pathway of the LAI risperidone formulation is via hepatic hydroxylation to 9-hydroxyrisperidone via CYP2D6 metabolism [93]. Missed doses of LAI risperidone should be administered as soon as possible [93]. Oral risperidone dose equivalents for the 90 and $120 \mathrm{mg}$ LAI doses are $3 \mathrm{mg}$ daily and $4 \mathrm{mg}$ daily, respectively [93].

\section{Discussion}

Patients with schizophrenia often have poor adherence to oral antipsychotics, and high relapse rates pose challenges to both patients and clinicians in the management of the disease [94-97]. LAI antipsychotics with unique pharmacokinetic profiles and novel mechanisms of delivery have been developed in an attempt to address this issue. In addition to the benefits of reduced treatment gaps with LAI versus oral antipsychotics, studies, particularly those in real-world samples, have demonstrated reduced psychopathology, relapses, hospitalizations, and mortality risk with LAI formulations [98-104]. To maximize the benefits associated with any particular LAI antipsychotic, it is necessary to understand both the pharmacokinetic and physical characteristics of LAI antipsychotics, which have implications for the proper dosing, preparation, and administration of these medications. Misunderstanding and misapplication of the pharmacokinetic differences between oral and LAI forms of the same antipsychotic as well as differences between LAI antipsychotics may affect decision making for clinicians and reduce the efficacy and tolerability of the prescribed medication in their patients. The present review facilitates understanding of pragmatic physical and formulation properties as well as 
clinically relevant pharmacokinetic data to help guide clinicians in ensuring effective and appropriate usage of these medications.

Data from a qualitative study of physician perspectives collected from focus group sessions among psychiatrists in Canada suggest that some clinicians may have limited knowledge about and experience with LAI antipsychotics, including the different LAIs available, and the evidence supporting their use [105]. The surveyed psychiatrists mentioned that a lack of confidence around their knowledge of LAI data contributed to the low LAI usage rate in their practices [105]. Clinicians who are less familiar with LAI antipsychotics may assume that the more familiar pharmacokinetic characteristics of oral antipsychotics can simply be extrapolated and applied to LAI antipsychotics. However, the parameters from oral agents cannot simply be multiplied to determine equivalent dosages for LAIs. For example, providing two injections of an LAI does not provide the same effect as taking twice as much of an oral formulation, since LAIs exhibit flip-flop kinetics, whereby the slow rate of absorption is the rate-limiting step in defining apparent half-life and time to steady state. Also, LAIs have more restrictive dose limitations than oral treatments; however, high-dose LAI treatment has not been shown to be superior to LAI treatment at doses within the identified therapeutic range [106-108].

Antipsychotic treatment should be individualized based on the patient's symptom profile and severity of symptoms, demographic characteristics, and medical history, including comorbidities and concomitant medications. When prescribing an LAI antipsychotic, clinicians should identify the optimally efficacious and well-tolerated dose of an oral antipsychotic before switching patients to the LAI formulation. This may not necessitate reinitiating treatment with the oral formulation if patients have a known history of responding to and tolerating a dose. As previously noted, $\mathrm{AL}_{\mathrm{NCD}}$ can be initiated with one dose of oral aripiprazole. After conversion of the oral dose that is efficacious and tolerated to the LAI dose, LAI antipsychotics should be allowed 5 half-lives (if a range of half-lives is indicated, using the largest value in the range) to achieve steady state; earlier dose adjustments will complicate dose finding. The apparent half-lives of respective LAI antipsychotics allow for different dosing schedules across various formulations (e.g., aripiprazole lauroxil vs. aripiprazole monohydrate; PP1M vs. PP3M). However, one limitation of LAI antipsychotics is that fewer dosage strengths are available. PP1M, PP3M, and aripiprazole lauroxil have five, four, and three available oral dose equivalents, respectively, whereas olanzapine pamoate and RLAI-polymer have two and aripiprazole monohydrate has one. Another limitation of LAI antipsychotics is that their long half-lives may prolong duration of adverse effects.
Therefore, tolerability should be assessed using shorteracting preparations before longer-acting formulations are initiated.

Importantly, to achieve and maintain therapeutic blood levels of LAI antipsychotics and minimize the risk of breakthrough psychotic symptoms [109, 110], proper dose preparation and administration is required [111], including a deep intramuscular injection (subcutaneous injection in the case of RLAI-polymer) to avoid loss of medication into the fat tissue and appropriate monitoring of injections taking place within the recommended time window. When dosing olanzapine pamoate, consider the risks of PDSS, which may occur with higher doses [112]. When scheduling patients, always consider that patients may be arriving for their appointment later than scheduled. Unless this deviation from the scheduled time is recorded and taken into account when scheduling the next injection, patients may accumulate delayed injection days, which can systematically reduce antipsychotic blood levels over time.

In addition to understanding the pharmacokinetic nuances of LAI antipsychotics, clinicians must always tailor the selection of a specific LAI antipsychotic, formulation, dose, and frequency to the individual patient's needs, preferences, and treatment goals.

\section{Conclusions}

LAI antipsychotics offer numerous benefits over oral antipsychotics and may delay the clinical and functional deterioration associated with cumulative relapses. However, oral and LAI formulations are not interchangeable, and clinicians must fully understand the unique and variable pharmacokinetic characteristics of different LAI antipsychotics to make effective use of these treatments to optimize patient outcomes.

Acknowledgements Writing and editorial support were provided by Jessica Kim (MedErgy) and ApotheCom (US and UK) and were funded by Janssen Global Services, LLC.

\section{Declarations}

Funding Open Access was funded by Janssen Global Services, LLC. This work was sponsored by Janssen Research and Development, LLC. Janssen Research and Development and Scientific Affairs, LLC reviewed the manuscript.

Conflict of Interest SRS is an employee of The University of Texas at Austin, College of Pharmacy, Pharmacotherapy Division. He was appointed to the Texas Health and Human Services Commission, San Antonio State Hospital and the UT Health San Antonio, Long School of Medicine; has been a consultant for Alkermes, Intra-Cellular Therapies, Genomind, Karuna, and Otsuka; has participated in speakers bureaux for Alkermes, Intra-Cellular Therapies, Neurocrine, and Teva; 
has served as speaker for several professional organizations; has been on the Business Development Council for the College of Psychiatric and Neurologic Pharmacists; was the Treasurer (term ended 2019) for the College of Psychiatric and Neurologic Pharmacists Foundation; and has served as an expert witness on both defendant and plaintiff sides. He has no direct stock ownership in pharmaceutical corporations. CUC has been a consultant and/or advisor to or has received honoraria from Acadia, Alkermes, Allergan, Angelini, Axsome, Gedeon Richter, Gerson Lehrman Group, Intra-Cellular Therapies, Janssen/ J\&J, LB Pharma, Lundbeck, MedAvante-ProPhase, Medscape, Neurocrine, Noven, Otsuka, Pfizer, Recordati, Rovi, Sumitomo Dainippon, Sunovion, Supernus, Takeda, and Teva. He has provided expert testimony for Janssen and Otsuka; served on a data safety monitoring board for Lundbeck, Rovi, Supernus, and Teva; received grant support from the Berlin Institute of Health, Janssen, the National Institute of Mental Health, the Patient-Centered Outcomes Research Institute, Takeda, and the Thrasher Foundation; and received royalties from UpToDate. $\mathrm{He}$ is also a stock option holder of LB Pharma. JKS, SG, MM, WH, and RV are employees and shareholders of Johnson \& Johnson. EK is a former employee and shareholder of Johnson \& Johnson.

Ethics approval Not applicable.

Consent to participate Not applicable.

Consent for publication Not applicable.

Availability of data and material The data-sharing policy of Janssen Pharmaceutical Companies of Johnson \& Johnson is available at https ://www.janssen.com/clinical-trials/transparency. As noted on this site, requests for access to the study data can be submitted through the Yale Open Data Access Project site at https://yoda.yale.edu.

Code availability Not applicable.

Author contributions All authors contributed to the design of the search algorithm, to the analysis of the results and to the writing of the manuscript. All authors approved the final version of this manuscript. Conceptualization: CUC, EK (lead), JKS, WH, MM, RV, SRS. Methodology: CUC, EK, JKS, WH, SG, MM, SRS. Formal analysis and investigation: EK, MM. Writing - original draft preparation: EK, JKS, SG, MM. Writing - review and editing: CUC, EK, JKS, WH, SG, MM, RV, SRS. Funding acquisition: EK (lead), MM. Resources: EK (lead), MM. Data curation: EK, JKS, WH, MM. Supervision: CUC, EK (lead), MM, SRS. Investigation: EK, SG, MM. Project administration: EK, MM. Software: EK, MM. Validation: EK, MM. Visualization: EK, MM, RV, SRS.

Open Access This article is licensed under a Creative Commons Attribution-NonCommercial 4.0 International License, which permits any non-commercial use, sharing, adaptation, distribution and reproduction in any medium or format, as long as you give appropriate credit to the original author(s) and the source, provide a link to the Creative Commons licence, and indicate if changes were made. The images or other third party material in this article are included in the article's Creative Commons licence, unless indicated otherwise in a credit line to the material. If material is not included in the article's Creative Commons licence and your intended use is not permitted by statutory regulation or exceeds the permitted use, you will need to obtain permission directly from the copyright holder. To view a copy of this licence, visit http://creativecommons.org/licenses/by-nc/4.0/.

\section{References}

1. Kahn RS, Sommer IE, Murray RM, Meyer-Lindenberg A, Weinberger DR, Cannon TD, et al. Schizophrenia. Nat Rev Dis Primers. $2015 ; 1: 15067$.

2. Correll CU, Rubio JM, Kane JM. What is the risk-benefit ratio of long-term antipsychotic treatment in people with schizophrenia? World Psychiatry. 2018;17(2):149-60.

3. Lehman AF, Lieberman JA, Dixon LB, McGlashan TH, Miller $\mathrm{AL}$, Perkins DO, et al. Practice guideline for the treatment of patients with schizophrenia. 2nd ed. Washington: American Psychiatric Association; 2010.

4. Kaplan G, Casoy J, Zummo J. Impact of long-acting injectable antipsychotics on medication adherence and clinical, functional, and economic outcomes of schizophrenia. Patient Prefer Adherence. 2013;7:1171-80.

5. Weiden PJ. Redefining medication adherence in the treatment of schizophrenia: how current approaches to adherence lead to misinformation and threaten therapeutic relationships. Psychiatr Clin N Am. 2016;39(2):199-216.

6. Lacro JP, Dunn LB, Dolder CR, Leckband SG, Jeste DV. Prevalence of and risk factors for medication nonadherence in patients with schizophrenia: a comprehensive review of recent literature. J Clin Psychiatry. 2002;63(10):892-909.

7. Weiden PJ, Kozma C, Grogg A, Locklear J. Partial compliance and risk of rehospitalization among California Medicaid patients with schizophrenia. Psychiatr Serv. 2004;55(8):886-91.

8. Cropley VL, Klauser P, Lenroot RK, Bruggemann J, Sundram S, Bousman C, et al. Accelerated gray and white matter deterioration with age in schizophrenia. Am J Psychiatry. 2017;174(3):286-95.

9. Vita A, De PL, Deste G, Sacchetti E. Progressive loss of cortical gray matter in schizophrenia: a meta-analysis and meta-regression of longitudinal MRI studies. Transl Psychiatry. 2012;2:e190.

10. Wiersma D, Nienhuis FJ, Slooff CJ, Giel R. Natural course of schizophrenic disorders: a 15-year followup of a Dutch incidence cohort. Schizophr Bull. 1998;24(1):75-85.

11. Emsley R, Nuamah I, Hough D, Gopal S. Treatment response after relapse in a placebo-controlled maintenance trial in schizophrenia. Schizophr Res. 2012;138(1):29-34.

12. Takeuchi H, Siu C, Remington G, Fervaha G, Zipursky RB, Foussias G, et al. Does relapse contribute to treatment resistance? Antipsychotic response in first- vs second-episode schizophrenia. Neuropsychopharmacology. 2019;44(6):1036-42.

13. McEvoy JP. Risks versus benefits of different types of long-acting injectable antipsychotics. J Clin Psychiatry. 2006;67(Suppl 5):15-8.

14. Quan DJ. A primer on pharmacokinetics. Nephrol Nurs J. 2008;35(2):213-5.

15. Fan J, De Lannoy IA. Pharmacokinetics. Biochem Pharmacol. 2014;87(1):93-120.

16. Florence AT, Jani PU. Novel oral drug formulations. Their potential in modulating adverse effects. Drug Saf. 1994;10(3):233-66.

17. Basson RP, Cerimele BJ, DeSante KA, Howey DC. Tmax: an unconfounded metric for rate of absorption in single dose bioequivalence studies. Pharm Res. 1996;13(2):324-8.

18. Mansoor A, Mahabadi N. Volume of distribution. Treasure Island: StatPearls Publishing LLC; 2020.

19. Waller DG, George CF. Prodrugs. Br J Clin Pharmacol. 1989;28(5):497-507.

20. Waller DG, Derek G, Sampson A. Pharmacokinetics. In: Medical pharmacology and therapeutics. 5th ed. Elsevier: Philadelphia; 2018. p. 33-62. 
21. SAPHRIS $®$ (asenapine) sublingual tablets [prescribing information]. Irvine, CA: Allergan, 2017.

22. Preskorn SH, Catterson ML. General principles of pharmacokinetics. In: Preskorn SH, Feighner JP, Stanga CY, Ross R, editors. Antidepressants: past, present and future. Berlin: Springer; 2004. p. 35-86.

23. Kennedy WK, Jann MW, Kutscher EC. Clinically significant drug interactions with atypical antipsychotics. CNS Drugs. 2013;27(12):1021-48.

24. Miah MK, Shaik IH, Feturi FG, Ali A, Venkataramanan R. Clinical pharmacokinetics. clinical pharmacy education, practice and research: clinical pharmacy, drug information, pharmacovigilance, pharmacoeconomics and clinical research. Philadelphia: Elsevier; 2019.

25. Kenakin TP. A pharmacology primer: theory, applications, and methods. 3rd ed. Burlington: Elsevier Academic Press; 2009.

26. Moons T, de Roo M, Claes S, Dom G. Relationship between P-glycoprotein and second-generation antipsychotics. Pharmacogenomics. 2011;12(8):1193-211.

27. Ragia G, Dahl ML, Manolopoulos VG. Influence of CYP3A5 polymorphism on the pharmacokinetics of psychiatric drugs. Curr Drug Metab. 2016;17(3):227-36.

28. Lynch T, Price A. The effect of cytochrome P450 metabolism on drug response, interactions, and adverse effects. Am Fam Physician. 2007;76(3):391-6.

29. US National Library of Medicine. Genetics Home Reference. Cytochrome, p 450. 2020. https://ghr.nlm.nih.gov/primer/genef amily/cytochromep450. Accessed 23 June 2020.

30. Klotz U. Pharmacokinetics and drug metabolism in the elderly. Drug Metab Rev. 2009;41(2):67-76.

31. Ogu CC, Maxa JL. Drug interactions due to cytochrome P450. Proc (Bayl Univ Med Cent). 2000;13(4):421-3.

32. Yáñez JA, Remsberg CM, Sayre CL, Forrest ML, Davies NM. Flip-flop pharmacokinetics-delivering a reversal of disposition: challenges and opportunities during drug development. Ther Deliv. 2011;2(5):643-72.

33. Spanarello S, La FT. The pharmacokinetics of long-acting antipsychotic medications. Curr Clin Pharm. 2014;9(3):310-7.

34. Soliman E, Ranjan S, Xu T, Gee C, Harker A, Barrera A, et al. A narrative review of the success of intramuscular gluteal injections and its impact in psychiatry. Biodes Manuf. 2018;1(3):161-70.

35. Zuidema J, Pieters FAJM, Duchateau GSMJE. Release and absorption rate aspects of intramuscularly injected pharmaceuticals. Int J Pharm. 1988;47(1):1-12.

36. Sheehan JJ, Reilly KR, Fu DJ, Alphs L. Comparison of the peakto-trough fluctuation in plasma concentration of long-acting injectable antipsychotics and their oral equivalents. Innov Clin Neurosci. 2012;9(7-8):17-23.

37. Beresford R, Ward A. Haloperidol decanoate. A preliminary review of its pharmacodynamic and pharmacokinetic properties and therapeutic use in psychosis. Drugs. 1987;33(1):31-49.

38. Deberdt R, Elens P, Berghmans W, Heykants J, Woestenborghs $\mathrm{R}$, Driesens F, et al. Intramuscular haloperidol decanoate for neuroleptic maintenance therapy. Efficacy, dosage schedule and plasma levels. An open multicenter study. Acta Psychiatr Scand. 1980;62(4):356-63.

39. Reyntigens AJ, Heykants JJ, Woestenborghs RJ, Gelders YG, Aerts TJ. Pharmacokinetics of haloperidol decanoate. A 2-year follow-up. Int Pharmacopsychiatry. 1982;17(4):238-46.

40. Salzman PM, Raoufinia A, Legacy S, Such P, Eramo A. Plasma concentrations and dosing of 2 long-acting injectable formulations of aripiprazole. Neuropsychiatr Dis Treat. 2017;13:1125-9.

41. Ehret MJ, Davis E, Luttrell SE, Clark C. Aripiprazole Lauroxil NanoCrystal(®) Dispersion Technology (Aristada Initio(®)). Clin Schizophr Relat Psychoses. 2018;12(2):92-6.
42. Jann MW, Ereshefsky L, Saklad SR. Clinical pharmacokinetics of the depot antipsychotics. Clin Pharmacokinet. 1985;10(4):315-33.

43. Vermeir M, Naessens I, Remmerie B, Mannens G, Hendrickx $\mathrm{J}$, Sterkens $\mathrm{P}$, et al. Absorption, metabolism, and excretion of paliperidone, a new monoaminergic antagonist, in humans. Drug Metab Dispos. 2008;36(4):769-79.

44. Jørgensen A, Andersen J, Bjørndal N, Dencker SJ, Lundin L, Malm U. Serum concentrations of $c i s(\mathrm{Z})$-flupentixol and prolactin in chronic schizophrenic patients treated with flupentixol and $\operatorname{cis}(\mathrm{Z})$-flupentixol decanoate. Psychopharmacology. 1982;77(1):58-65.

45. FLUANXOL ${ }^{\circledR}$ DEPOT (flupentixol decanoate) intramuscular injection [product monograph]. Montreal, QC: Lundbeck Canada Inc.; 2017.

46. FLUANXOL ${ }^{\circledR}$ (flupentixol dihydrochloride) tablets [product monograph]. Montreal, QC: Lundbeck Canada Inc.; 2017.

47. Bailey L, Taylor D. Estimating the optimal dose of flupentixol decanoate in the maintenance treatment of schizophreniaa systematic review of the literature. Psychopharmacology. 2019;236(11):3081-92.

48. Dencker SJ, Johansson R, Malm U. Pharmacokinetic and pharmacodynamic studies on high doses of fluphenazine. Psychopharmacology. 1988;94(2):237-41.

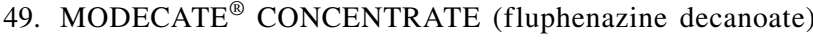
injection [product monograph]. Montreal, QC: Bristol-Myers Squibb Canada; 2017.

50. Gelenberg AJ. Significant greater loss of medication from the injection site when fluphenazine (Prolixin) decanoate was injected intramuscularly as contrasted with subcutaneously. J Clin Psychiatry. 1987;48(10):425.

51. Soni SD, Wiles D, Schiff AA, Bamrah JS. Plasma levels of fluphenazine decanoate. Effects of site of injection, massage and muscle activity. Br J Psychiatry. 1988;153:382-4.

52. Kane JM, Rifkin A, Quitkin F, Nayak D, Saraf K, Ramos-Lorenzi $\mathrm{JR}$, et al. Low dose fluphenazine decanoate in maintenance treatment of schizophrenia. Psychiatry Res. 1979;1(3):341-8.

53. Fluphenazine decanoate injection, USP (product monograph). Schaumburg, IL: APP Pharmaceuticals, LLC; 2010.

54. Haldol decanoate (haloperidol) for IM injection only [prescribing information]. Titusville, NJ: Janssen Pharmaceuticals, Inc.; 2019.

55. McEvoy JP, Byerly M, Hamer RM, Dominik R, Swartz MS, Rosenheck RA, et al. Effectiveness of paliperidone palmitate vs haloperidol decanoate for maintenance treatment of schizophrenia: a randomized clinical trial. JAMA. 2014;311(19):1978-87.

56. Brissos S, Veguilla MR, Taylor D, Balanza-Martinez V. The role of long-acting injectable antipsychotics in schizophrenia: a critical appraisal. Ther Adv Psychopharmacol. 2014;4(5):198-219.

57. Wei FC, Jann MW, Lin HN, Piao-Chien C, Chang WH. A practical loading dose method for converting schizophrenic patients from oral to depot haloperidol therapy. J Clin Psychiatry. 1996;57(7):298-302.

58. Panagiotidis G, Arthur HW, Lindh JD, Dahl ML, Sjöqvist F. Depot haloperidol treatment in outpatients with schizophrenia on monotherapy: impact of CYP2D6 polymorphism on pharmacokinetics and treatment outcome. Ther Drug Monit. 2007;29(4):417-22.

59. CLOPIXOL ${ }^{\circledR}$ (zuclopenthixol decanoate) tablets [product monograph]. Montreal, QC: Lundbeck Canada Inc.; 2014.

60. Viala A, Ba B, Durand A, Gouezo F, Hou N, Jørgensen A. Comparative study of the pharmacokinetics of zuclopenthixol decanoate and fluphenazine decanoate. Psychopharmacology. 1988;94(3):293-7.

61. ABILIFY MAINTENA® (aripiprazole) for extended-release injectable suspension, for intramuscular use [package insert]. Rockville, MD: Otsuka America Pharmaceuticals Inc.; 2020. 
62. Raoufinia A, Peters-Strickland T, Nylander AG, Baker RA, Eramo A, Jin N, et al. Aripiprazole once-monthly $400 \mathrm{mg}$ : comparison of pharmacokinetics, tolerability, and safety of deltoid versus gluteal administration. Int $\mathbf{J}$ Neuropsychopharmacol. 2017;20(4):295-304.

63. Hard ML, Mills RJ, Sadler BM, Turncliff RZ, Citrome L. Aripiprazole lauroxil: pharmacokinetic profile of this long-acting injectable antipsychotic in persons with schizophrenia. J Clin Psychopharmacol. 2017;37(3):289-95.

64. Center for Drug Evaluation and Research. Clinical pharmacology and biopharmaceutics review(s) INVEGA SUSTENNA ${ }^{\mathrm{TM}}$ (paliperidone palmitate). 2009. https://www.accessdata.fda.gov/ drugsatfda_docs/nda/2009/022264s000clinpharmr.pdf. Accessed 11 Nov 2020

65. Center for Drug Evaluation and Research. Summary Review. Recommendation for approval action for Invega Sustenna (paliperidone palmitate) for schizophrenia (both acute and maintenance efficacy). 2009. https://www.accessdata.fda.gov/drugs atfda_docs/nda/2009/022264s000sumr.pdf. Accessed 11 Nov 2020.

66. Hard ML, Mills RJ, Sadler BM, Wehr AY, Weiden PJ, von Moltke L. Pharmacokinetic profile of a 2-month dose regimen of aripiprazole lauroxil: a phase i study and a population pharmacokinetic model. CNS Drugs. 2017;31(7):617-24.

67. ARISTADA ${ }^{\circledR}$ (aripiprazole lauroxil) extended-release injectable suspension, for intramuscular use [prescribing information]. Waltham, MA: Alkermes, Inc.; 2020.

68. Hard ML, Wehr AY, Du Y, Weiden PJ, Walling D, von Moltke L. Pharmacokinetic evaluation of a 1-day treatment initiation option for starting long-acting aripiprazole lauroxil for schizophrenia. J Clin Psychopharmacol. 2018;38(5):435-41.

69. ARISTADA INITIO ${ }^{\mathrm{TM}}$ (aripiprazole lauroxil) extended-release injectable suspension [product monograph]. Waltham, MA: Alkermes, Inc.; 2020.

70. Heres S, Kraemer S, Bergstrom RF, Detke HC. Pharmacokinetics of olanzapine long-acting injection: the clinical perspective. Int Clin Psychopharmacol. 2014;29(6):299-312.

71. Mitchell M, Kothare P, Bergstrom R, Zhao F, Jen KY, Walker $\mathrm{D}$, et al. Single- and multiple-dose pharmacokinetic, safety, and tolerability profiles of olanzapine long-acting injection: an openlabel, multicenter, nonrandomized study in patients with schizophrenia. Clin Ther. 2013;35(12):1890-908.

72. ZYPREXA RELPREVV (olanzapine) for extended release injectable suspension [prescribing information]. Indianapolis, IN: Eli Lilly and Company; 2020.

73. Detke HC, Zhao F, Garhyan P, Carlson J, McDonnell D. Dose correspondence between olanzapine long-acting injection and oral olanzapine: recommendations for switching. Int Clin Psychopharmacol. 2011;26(1):35-42.

74. Russu A, Kern Sliwa J, Ravenstijn P, Singh A, Mathews M, Kim E, et al. Maintenance dose conversion between oral risperidone and paliperidone palmitate 1 month: practical guidance based on pharmacokinetic simulations. Int J Clin Pract. 2018;72(6):e13089.

75. Rossenu S, Cleton A, Hough D, Crauwels H, Vandebosch A, Berwaerts J, et al. Pharmacokinetic profile after multiple deltoid or gluteal intramuscular injections of paliperidone palmitate in patients with schizophrenia. Clin Pharmacol Drug Dev. 2015;4(4):270-8.

76. Cleton A, Rossenu S, Crauwels H, Berwaerts J, Hough D, Gopal S, et al. A single-dose, open-label, parallel, randomized, dose-proportionality study of paliperidone after intramuscular injections of paliperidone palmitate in the deltoid or gluteal muscle in patients with schizophrenia. J Clin Pharmacol. 2014;54(9):1048-57.
77. INVEGA SUSTENNA ${ }^{\circledR}$ (paliperidone palmitate) extendedrelease injectable suspension, for intramuscular use [prescribing information]. Beerse, Belgium: Janssen Pharmaceutica NV; 2019. p. 18.

78. Samtani MN, Vermeulen A, Stuyckens K. Population pharmacokinetics of intramuscular paliperidone palmitate in patients with schizophrenia: a novel once-monthly, long-acting formulation of an atypical antipsychotic. Clin Pharmacokinet. 2009;48(9):585-600.

79. Helland A, Spigset O. Serum concentrations of paliperidone after administration of the long-acting injectable formulation. Ther Drug Monit. 2017;39(6):659-62.

80. Coppola D, Liu Y, Gopal S, Remmerie B, Samtani MN, Hough DW, et al. A one-year prospective study of the safety, tolerability and pharmacokinetics of the highest available dose of paliperidone palmitate in patients with schizophrenia. BMC Psychiatry. 2012;12:26.

81. INVEGA TRINZA ${ }^{\circledR}$ (paliperidone palmitate) extended-release injectable suspension, for intramuscular use [prescribing information]. Titusville, NJ: Janssen Pharmaceuticals, Inc.; 2019.

82. Ravenstijn P, Remmerie B, Savitz A, Samtani MN, Nuamah I, Chang CT, et al. Pharmacokinetics, safety, and tolerability of paliperidone palmitate 3 -month formulation in patients with schizophrenia: a phase-1, single-dose, randomized, open-label study. J Clin Pharmacol. 2016;56(3):330-9.

83. Schoretsanitis G, Spina E, Hiemke C, de Leon J. A systematic review and combined analysis of therapeutic drug monitoring studies for long-acting paliperidone. Expert Rev Clin Pharmacol. 2018;11(12):1237-53.

84. RISPERDAL CONSTA ${ }^{\circledR}$ (risperidone) long-acting injection [prescribing information]. Titusville, NJ: Janssen Pharmaceuticals, Inc.; 2020.

85. Wilson WH. A visual guide to expected blood levels of long-acting injectable risperidone in clinical practice. J Psychiatr Pract. 2004;10(6):393-401.

86. Thyssen A, Rusch S, Herben V, Quiroz J, Mannaert E. Risperidone long-acting injection: pharmacokinetics following administration in deltoid versus gluteal muscle in schizophrenic patients. J Clin Pharmacol. 2010;50(9):1011-21.

87. Gharabawi GM, Gearhart NC, Lasser RA, Mahmoud RA, Zhu Y, Mannaert E, et al. Maintenance therapy with once-monthly administration of long-acting injectable risperidone in patients with schizophrenia or schizoaffective disorder: a pilot study of an extended dosing interval. Ann Gen Psychiatry. 2007;6:3.

88. Gefvert O, Eriksson B, Persson P, Helldin L, Bjorner A, Mannaert $\mathrm{E}$, et al. Pharmacokinetics and D2 receptor occupancy of long-acting injectable risperidone (Risperdal ConstaT) in patients with schizophrenia. Int J Neuropsychopharmacol. 2005;8(1):27-36.

89. Lee LH, Choi C, Collier AC, Barr AM, Honer WG, Procyshyn RM. The pharmacokinetics of second-generation long-acting injectable antipsychotics: limitations of monograph values. CNS Drugs. 2015;29(12):975-83.

90. Laffont CM, Gomeni R, Zheng B, Heidbreder C, Fudala PJ, Nasser AF. Population pharmacokinetics and prediction of dopamine D2 receptor occupancy after multiple doses of RBP-7000, a new sustained-release formulation of risperidone, in schizophrenia patients on stable oral risperidone treatment. Clin Pharmacokinet. 2014;53(6):533-43.

91. Laffont CM, Gomeni R, Zheng B, Heidbreder C, Fudala PJ, Nasser AF. Population pharmacokinetic modeling and simulation to guide dose selection for RBP-7000, a new sustained-release formulation of risperidone. J Clin Pharmacol. 2015;55(1):93-103.

92. Gomeni R, Heidbreder C, Fudala PJ, Nasser AF. A model-based approach to characterize the population pharmacokinetics and 
the relationship between the pharmacokinetic and safety profiles of RBP-7000, a new, long-acting, sustained-released formulation of risperidone. J Clin Pharmacol. 2013;53(10):1010-9.

93. PERSERIS (risperidone) for extended-release injectable suspension, for subcutaneous use [prescribing information]. North Chesterfield, VA: Indivior Inc.; 2019. p. 37.

94. Robinson D, Woerner MG, Alvir JM, Bilder R, Goldman R, Geisler $\mathrm{S}$, et al. Predictors of relapse following response from a first episode of schizophrenia or schizoaffective disorder. Arch Gen Psychiatry. 1999;56(3):241-7.

95. Olivares JM, Sermon J, Hemels M, Schreiner A. Definitions and drivers of relapse in patients with schizophrenia: a systematic literature review. Ann Gen Psychiatry. 2013;12(1):32.

96. Carbon M, Correll CU. Clinical predictors of therapeutic response to antipsychotics in schizophrenia. Dialogues Clin Neurosci. 2014;16(4):505-24.

97. Kane JM, Kishimoto T, Correll CU. Non-adherence to medication in patients with psychotic disorders: epidemiology, contributing factors and management strategies. World Psychiatry. 2013;12(3):216-26.

98. Kishimoto T, Nitta M, Borenstein M, Kane JM, Correll CU. Long-acting injectable versus oral antipsychotics in schizophrenia: a systematic review and meta-analysis of mirror-image studies. J Clin Psychiatry. 2013;74(10):957-65.

99. Kishimoto T, Hagi K, Nitta M, Leucht S, Olfson M, Kane $\mathrm{JM}$, et al. Effectiveness of long-acting injectable vs oral antipsychotics in patients with schizophrenia: a meta-analysis of prospective and retrospective cohort studies. Schizophr Bull. 2018;44(3):603-19.

100. Correll CU, Citrome L, Haddad PM, Lauriello J, Olfson M, Calloway SM, et al. The use of long-acting injectable antipsychotics in schizophrenia: evaluating the evidence. J Clin Psychiatry. 2016;77(Suppl 3):1-24.

101. Taipale H, Mittendorfer-Rutz E, Alexanderson K, Majak M, Mehtälä J, Hoti F, et al. Antipsychotics and mortality in a nationwide cohort of 29,823 patients with schizophrenia. Schizophr Res. 2018;197:274-80.

102. Taipale H, Mehtälä J, Tanskanen A, Tiihonen J. Comparative effectiveness of antipsychotic drugs for rehospitalization in schizophrenia-a nationwide study with 20 -year follow-up. Schizophr Bull. 2018;44(6):1381-7.

103. Tiihonen J, Mittendorfer-Rutz E, Majak M, Mehtälä J, Hoti F, Jedenius E, et al. Real-world effectiveness of antipsychotic treatments in a nationwide cohort of 29,823 patients with schizophrenia. JAMA Psychiatry. 2017;74(7):686-93.

104. Russu A, Savitz A, Mathews M, Gopal S, Feng Y, Samtani MN. Pharmacokinetic-pharmacodynamic characterization of relapse risk for paliperidone palmitate 1-month and 3-month formulations. J Clin Psychopharmacol. 2019;39(6):567-74.

105. Iyer S, Banks N, Roy MA, Tibbo P, Williams R, Manchanda R, et al. A qualitative study of experiences with and perceptions regarding long-acting injectable antipsychotics: part II-physician perspectives. Can J Psychiatry. 2013;58(5 Suppl 1):s23-9.

106. Takeuchi H, MacKenzie NE, Samaroo D, Agid O, Remington G, Leucht S. Antipsychotic dose in acute schizophrenia: a metaanalysis. Schizophr Bull. 2020;46(6):1439-58.

107. Leucht S, Crippa A, Siafis S, Patel MX, Orsini N, Davis JM. Dose-response meta-analysis of antipsychotic drugs for acute schizophrenia. Am J Psychiatry. 2020;177(4):342-53.

108. Smith RC, Leucht S, Davis JM. Maximizing response to first-line antipsychotics in schizophrenia: a review focused on finding from meta-analysis. Psychopharmacology. 2019;236(2):545-59.

109. Emsley R, Asmal L, Rubio JM, Correll CU, Kane JM. Predictors of psychosis breakthrough during 24 months of longacting antipsychotic maintenance treatment in first episode schizophrenia. Schizophr Res. 2020;225:55-62. https://doi. org/10.1016/j.schres.2019.11.025.

110. Rubio JM, Taipale H, Correll CU, Tanskanen A, Kane JM, Tiihonen J. Psychosis breakthrough on antipsychotic maintenance: results from a nationwide study. Psychol Med. 2019;50(8):1356-67.

111. Correll CU, Sliwa JK, Najarian DM, Saklad SR. Practical considerations for managing breakthrough psychosis and symptomatic worsening in patients with schizophrenia on long-acting injectable antipsychotics. CNS Spectr. 2018;24(4):354-70.

112. McDonnell DP, Detke HC, Bergstrom RF, Kothare P, Johnson J, Stickelmeyer M, et al. Post-injection delirium/sedation syndrome in patients with schizophrenia treated with olanzapine long-acting injection, II: investigations of mechanism. BMC Psychiatry. 2010;10:45.

113. HALDOL $\AA$ brand of haloperidol injection (for immediate release). Titusville, NJ: Janssen Pharmaceuticals, Inc.; 2020. p. 18.

114. Hough D, Lindenmayer JP, Gopal S, Melkote R, Lim P, Herben $\mathrm{V}$, et al. Safety and tolerability of deltoid and gluteal injections of paliperidone palmitate in schizophrenia. Prog Neuropsychopharmacol Biol Psychiatry. 2009;33(6):1022-31.

115. Magnusson MO, Samtani MN, Plan EL, Jonsson EN, Rossenu $\mathrm{S}$, Vermeulen A, et al. Population pharmacokinetics of a novel once-every 3 months intramuscular formulation of paliperidone palmitate in patients with schizophrenia. Clin Pharmacokinet. 2017;56(4):421-33.

116. Ivaturi V, Gopalakrishnan M, Gobburu JVS, Zhang W, Liu $\mathrm{Y}$, Heidbreder C, et al. Exposure-response analysis after subcutaneous administration of RBP-7000, a once-a-month longacting Atrigel formulation of risperidone. Br J Clin Pharmacol. 2017;83(7):1476-98.

117. Davies SJ, Westin AA, Castberg I, Lewis G, Lennard MS, Taylor $\mathrm{S}$, et al. Characterisation of zuclopenthixol metabolism by in vitro and therapeutic drug monitoring studies. Acta Psychiatr Scand. 2010;122(6):444-53.

118. Mallikaarjun S, Kane JM, Bricmont P, McQuade R, Carson W, Sanchez R, et al. Pharmacokinetics, tolerability and safety of aripiprazole once-monthly in adult schizophrenia: an open-label, parallel-arm, multiple-dose study. Schizophr Res. 2013;150(1):281-8.

119. Mallikaarjun S, Salazar DE, Bramer SL. Pharmacokinetics, tolerability, and safety of aripiprazole following multiple oral dosing in normal healthy volunteers. J Clin Pharmacol. 2004;44(2):179-87.

120. Gopal S, Vermeulen A, Nandy P, Ravenstijn P, Nuamah I, Buron Vidal JA, et al. Practical guidance for dosing and switching from paliperidone palmitate 1 monthly to 3 monthly formulation in schizophrenia. Curr Med Res Opin. 2015;31(11):2043-54.

121. Turncliff R, Hard M, Du Y, Risinger R, Ehrich EW. Relative bioavailability and safety of aripiprazole lauroxil, a novel oncemonthly, long-acting injectable atypical antipsychotic, following deltoid and gluteal administration in adult subjects with schizophrenia. Schizophr Res. 2014;159(2-3):404-10.

122. Ito S. Pharmacokinetics 101. Paediatr Child Health. 2011;16(9):535-6.

123. Cohen BM, Waternaux C, Chouinard G, Sommer BR, Jones B. Plasma levels of neuroleptic in patients receiving depot fluphenazine. J Clin Psychopharmacol. 1985;5(6):328-32.

124. Heresco-Levy U, Greenberg D, Lerer B, Javitt DC, Brown WA. Serum neuroleptic levels during reduced dose fluphenazine decanoate maintenance therapy. Isr J Psychiatry Relat Sci. 1997;34(4):281-9.

125. Eyles DW, Whiteford HA, Stedman TJ, Pond SM. Determination of haloperidol and reduced haloperidol in the plasma and 
blood of patients on depot haloperidol. Psychopharmacology. 1992;106(2):268-74.

126. Hard ML, Wehr AY, Sadler BM, Mills RJ, von Moltke L. Population pharmacokinetic analysis and model-based simulations of aripiprazole for a 1-day initiation regimen for the long-acting antipsychotic aripiprazole lauroxil. Eur J Drug Metab Pharmacokinet. 2018;43(4):461-9.

127. Risinger R, Hard M, Weiden PJ. A phase-1 study comparing pharmacokinetic and safety profiles of three different dose intervals of aripiprazole lauroxil. Psychopharmacol Bull. 2017;47(3):26-34.

128. Weiden PJ, Du Y, von Moltke L, Wehr A, Hard M, Marandi $\mathrm{M}$, et al. Pharmacokinetics, safety, and tolerability of a 2-month dose interval regimen of the long-acting injectable antipsychotic aripiprazole lauroxil: results from a 44-week phase i study. CNS Drugs. 2020;34(9):961-72.

129. Hard ML, Wehr A, von Moltke L, Du Y, Farwick S, Walling DP, et al. Pharmacokinetics and safety of deltoid or gluteal injection of aripiprazole lauroxil NanoCrystal(®) Dispersion used for initiation of the long-acting antipsychotic aripiprazole lauroxil. Ther Adv Psychopharmacol. 2019;9:2045125319859964.

130. Tveito M, Smith RL, Høiseth G, Molden E. The effect of valproic acid on olanzapine serum concentration: a study including 2791 patients treated with olanzapine tablets or long-acting injections. J Clin Psychopharmacol. 2019;39(6):561-6.
131. Gomeni R, Bressolle-Gomeni F, Fava M. Response surface analysis and nonlinear optimization algorithm for maximization of clinical drug performance: application to extended-release and long-acting injectable paliperidone. J Clin Pharmacol. 2016;56(10):1296-306.

132. Samtani MN, Sheehan JJ, Fu DJ, Remmerie B, Sliwa JK, Alphs L. Management of antipsychotic treatment discontinuation and interruptions using model-based simulations. Clin Pharmacol. 2012;4:25-40.

133. Si T, Su Y, Liu Y, Zhang H, Li H, Rui Q, et al. Pharmacokinetics and tolerability of paliperidone palmitate injection in Chinese subjects. Hum Psychopharmacol. 2014;29(2):203-10.

134. Samtani MN, Nuamah I, Gopal S, Remmerie B, Kern Sliwa J, Alphs L. Expansion of guidance for the day 8 initiation dose of paliperidone palmitate to avoid a missed dose. Neuropsychiatr Dis Treat. 2013;9:721-30.

135. Nesvåg R, Hendset M, Refsum $H$, Tanum L. Serum concentrations of risperidone and 9-OH risperidone following intramuscular injection of long-acting risperidone compared with oral risperidone medication. Acta Psychiatr Scand. 2006;114(1):21-6.

136. Eerdekens M, Van Hove I, Remmerie B, Mannaert E. Pharmacokinetics and tolerability of long-acting risperidone in schizophrenia. Schizophr Res. 2004;70(1):91-100. 